\title{
Revisiting the Delegation Problem in a Sticky Price and Wage Economy
}

\author{
Gregory E. Givens* \\ Assistant Professor of Economics \\ Department of Economics and Finance \\ Jennings A. Jones College of Business \\ Middle Tennessee State University \\ Murfreesboro, TN 37132 \\ ggivens@mtsu . edu
}

First Draft: October 2004

This Draft: February 2006

\begin{abstract}
In a stylized economy with price and wage stickiness, this paper argues that delegating a nominal wage target to a central bank operating under discretion generally delivers better social outcomes than delegating price level or inflation targets. Although both policies impart inertia into central bank actions, wage targeting dominates price level targeting because the former delivers a more favorable tradeoff between the stabilization goals appearing in the social welfare function, namely, price inflation, wage inflation, and the output gap. Delegation of a dual policy featuring both price level and nominal wage targets, however, nearly replicates the efficient outcome accompanying the precommitment policy from a timeless perspective.
\end{abstract}

Keywords: Price Level Targeting, Wage Targeting, Delegation, Timeless Perspective JEL Classification: E42, E50, E52, E58

\footnotetext{
*I would like to thank Michael Salemi and Richard Froyen for invaluable guidance and advice. I have also benefited from help discussions with Stanley Black, Patrick Conway, Eric Renault, Catalin Stefanescu, and participants of the UNC Macro-Money Seminar. All remaining errors and omissions are my own.
} 
Since the early 1990's, numerous countries that have formally adopted inflation targeting as a framework for monetary policy have gone on to accomplish a permanent reduction in the level and volatility of inflation. ${ }^{1}$ These developments have motivated a voluminous literature that examines the effects of inflation targeting policies in the context of various models of the economy (e.g., Svensson (1997), Rudebusch and Svensson (1999), and Svensson and Woodford (2005)). For conducting policy analysis, Svensson (1999a) argues that the stabilization objectives of an inflation targeting central bank can be usefully summarized with a social loss function defined over a weighted sum of the variances of inflation and the output gap. Moreover, the relative weight attached to the output gap objective determines how quickly inflation is returned to target in the aftermath of shocks.

In addition to the real-world success experienced by many inflation-targeting central banks, the case for jointly pursuing inflation and output gap objectives can also be made on the basis of theory. Recent work on the analysis of monetary policy has been conducted in the context of a class of models described by Goodfriend and King (1997) as the "New Neoclassical Synthesis." Models belonging to this family synthesize many of the dominant features of classical business cycle models, such as intertemporal optimization and rational expectations, with distinctively Keynesian elements like staggered price-setting (e.g., Rotemberg and Woodford (1997) and McCallum and Nelson (1999)). Because they are specified at the level of preferences, a natural criterion for policy evaluation is readily available, that is, the utility function of the representative consumer. Woodford (2003) demonstrates that under certain conditions, a quadratic loss function specifying price inflation and the output gap as explicit stabilization objectives constitutes a valid approximation to average household utility.

Although the evidence points to a common set of appropriate stabilization objectives

\footnotetext{
${ }^{1}$ Notable examples include New Zealand, Australia, the United Kingdom, Canada, and Sweden. For a more comprehensive list, see Mishkin and Schmidt-Hebbel (2002).
} 
for monetary policy, there is some dispute about how policy should be directed towards achieving those objectives. Svensson (1999b), Dittmar and Gavin (2000), and Vestin (2000), for instance, argue that assigning a price level target to a central bank operating under discretion actually delivers a more favorable inflation-output gap variance tradeoff than the pursuit of an inflation target. Jensen (2002), Walsh (2003), Nessén and Vestin (2005), and Söderström (2005) establish that similar improvements can be manufactured by assigning alternative target variables, such as the growth rate nominal income, the growth rate of output relative to potential, a multi-period average rate of inflation, or the growth rate of the money stock. The intuition for these seemingly contradictory results is as follows. In a model that emphasizes forward-looking behavior, inflation targeting under discretion fails to impart the inertial response to supply shocks observed under the fully optimal commitment policy. ${ }^{2}$ In contrast, stabilizing a variable that demonstrates intrinsic persistence (like the price level or nominal income growth) requires a sustained policy adjustment provided a real objective is also included in the loss function. If commitments are not possible, a discretionary central bank can engineer inertia by redirecting policy towards stabilizing any one of these alternative target variables.

In this paper I take the position that the central bank is unable to commit to an optimal policy, so the prevailing regime is one of discretion. The goal is to identify policies that achieve a set of recognized objectives embodied in a social loss function. To that end, I adopt the Rogoff (1985) concept of monetary delegation as a framework for policy. Delegation involves the action of two separate agents: a policymaker and a central banker. First, the policymaker empowers the central banker with the authority to conduct monetary operations through control of a short-term nominal interest rate. Second, the central banker moves to stabilize a set of target variables designated by the policymaker. The chosen target variables, represented by an assigned quadratic loss function, may be very different from

\footnotetext{
${ }^{2}$ Woodford (1999) describes this inefficiency as the "stabilization bias" of discretionary policymaking.
} 
those appearing in the true social loss function. Nevertheless, the policy weight coefficients associated with each variable are preselected to insure minimum social loss. In this way, monetary delegation can be viewed as the establishment of a particular targeting regime. I use these terms synonymously throughout the paper.

The analysis presented here departs from the current delegation literature along two important dimensions. One, each set of authors referenced above rely on models that implicitly assume only a single source of nominal stickiness. In light of recent contributions that collectively call into question the ability of sticky price models to generate plausible business cycle fluctuations (e.g., Chari, Kehoe, and McGratten (2000) and Christiano, Eichenbaum, and Evans (2005)), I use a version of the model developed by Erceg, Henderson, and Levin (2000) that incorporates two sources of nominal stickiness in the form of staggered prices and wages. Two, alternative targeting regimes are ranked on a welfare basis according to a social loss function that is derived by taking a quadratic approximation to the representative consumer's lifetime utility. As illustrated by Rotemberg and Woodford (1997) and Erceg et al. (2000), adoption of a utility-based measure of social loss reveals the stabilization objectives consistent with household optimization and determines the preference weights that the policymaker should attach to each. The model used in this paper implies three stabilization goals, goods-price inflation, nominal wage inflation, and the output gap. This step represents a departure from the existing delegation literature that consistently appeals to "ad hoc" welfare criteria normally defined over a weighted sum of the variances of price inflation and the output gap.

Using the delegation framework in the context of a sticky price and wage economy, I evaluate a set of alternative targeting regimes under discretion. The emphasis is on comparing outcomes under price level targeting to regimes that give prominence to a nominal wage target. Foreshadowing a number of the principal results, price level targeting regimes are often welfare-dominated by inflation targeting regimes when defined over a combination 
of goods-price and nominal wage inflation. The poor performance occurs despite the ability of the former to impart the kind of inertia that has been shown to generate improved outcomes in previous studies. Conversely, an optimally designed nominal wage target has more desirable stabilization properties that reduce the cost of achieving a given degree of price and wage inflation volatility. For numerous parameter configurations, wage targeting strictly dominates price level and inflation targeting. ${ }^{3}$ The results indicate, however, that wage targeting can be improved in most cases by jointly pursuing a price level target. In fact, a dual price and wage policy nearly replicates the optimal commitment equilibrium under the timeless perspective and is robust to significant variation in the underlying structural parameters. Finally, price and wage targeting policies are compared to a number of other regimes that have demonstrated good performance in single-friction models, in particular, interest rate smoothing (Woodford (1999)), speed limit policies (Walsh (2003)), nominal income growth (Jensen (2002)), and average inflation (Nessén and Vestin (2005)). Outcomes under wage targeting are shown to be quite competitive with these alternative regimes in a sticky price and wage framework.

The remainder of this paper is structured as follows. Section 1 presents the structural model and the corresponding social loss function. Section 2 characterizes the optimal equilibrium using the timeless perspective concept of commitment. Section 3 discusses the various targeting regimes considered and describes how to solve the optimal delegation problem. Section 4 records the performance of each regime and examines the sensitivity of the results to variations in the structural parameters. Within the sticky price and wage framework, section 5 compares the performance of price and wage targets to a number of alternatives studied in the existing literature. Section 6 concludes.

\footnotetext{
${ }^{3}$ This finding echoes the main conclusion reached by Canzoneri, Cumby and Diba (2004) and Levin, Onatski, Williams, and Williams (2005). Using a variety of different optimization-based models, each set of authors demonstrate that a simple instrument rule delivers a superior welfare outcome when it features contemporaneous feedback from nominal wage inflation alone.
} 


\section{A Sticky Price and Wage Model}

The economic model is a modified version of the one developed by Erceg et al. (2000) driven by shocks to productivity and aggregate supply. It belongs to a larger family of New Keynesian models that combine monopolistic competition and nominal rigidities in an optimizing-agent framework. Profit-maximizing firms set prices in a staggered fashion and manufacture differentiated products output using labor and a fixed quantity of capital. Utility-maximizing households choose optimal sequences of consumption and supply a differentiated variety of labor in monopolistically competitive factor markets. Households set wages according to the same staggering mechanism that firms use to set prices, and each pools the income risk associated with the constraints on price and wage-setting by trading in complete state-contingent securities markets.

\subsection{The Economy}

The aggregate demand component is derived from first principles by taking a log-linear approximation of the intertemporal Euler equation characterizing the representative household's optimal consumption path. Denote $x_{t}$ the output gap, or the log deviation of real output from a hypothetical level that would prevail in a "distortionless" economy absent nominal rigidities, and $\pi_{t}$ the inflation rate (log difference in the price level $p_{t}$ between periods $t-1$ and $t$ ). The output gap is determined by the familiar equilibrium condition

$$
x_{t}=E_{t} x_{t+1}-\sigma^{-1}\left(i_{t}-E_{t} \pi_{t+1}-r_{t}^{n}\right)
$$

where $i_{t}$ is the single-period nominal interest rate, and $E_{t}$ is the expectations operator conditional on information available through date $t$. The parameter $\sigma>0$ represents the inverse of the intertemporal elasticity of substitution, and $r_{t}^{n}$ is a stochastic disturbance 
summarizing the exogenous variation in the natural rate of interest, the equilibrium real interest rate obtained under flexible prices and wages.

The structural equations comprising aggregate supply are log-linear approximations of the first-order conditions of a dynamic general equilibrium problem in which monopolistically competitive firms and households stagger price and wage contracts in the manner pioneered by Calvo (1983). Denote $\pi_{t}^{w}$ the rate of wage inflation (log difference in the aggregate nominal wage $n_{t}$ between periods $t-1$ and $t$ ) and $w_{t}$ the log of the real wage. Goods-price and nominal wage inflation and the aggregate real wage are determined by the following conditions:

$$
\begin{aligned}
\pi_{t} & =\beta E_{t} \pi_{t+1}+\xi_{p}\left(\frac{\alpha}{1-\alpha}\right) x_{t}+\xi_{p}\left(w_{t}-w_{t}^{n}\right)+e_{\pi, t} \\
\pi_{t}^{w} & =\beta E_{t} \pi_{t+1}^{w}+\xi_{w}\left(\frac{\chi}{1-\alpha}+\sigma\right) x_{t}-\xi_{w}\left(w_{t}-w_{t}^{n}\right)+e_{w, t} \\
\pi_{t}^{w} & =w_{t}-w_{t-1}+\pi_{t}
\end{aligned}
$$

where $w_{t}^{n}$ is the natural real wage and $\beta \in(0,1)$ measures the subjective discount factor. ${ }^{4}$

The slope parameter $\xi_{p}$ measures the contemporaneous impact of variations in average real marginal cost on goods-price inflation. Likewise, $\xi_{w}$ determines the sensitivity of wage inflation to departures of the real wage from the households' average marginal rate of substitution between labor and consumption. Both parameters are nonlinear functions of the primitive coefficients governing the tastes and technologies of households and firms. Specifically,

$$
\xi_{p}=\frac{\left(1-\varepsilon_{p}\right)\left(1-\beta \varepsilon_{p}\right)}{\varepsilon_{p}\left(1+\frac{\alpha}{1-\alpha} \theta\right)} \quad \text { and } \quad \xi_{w}=\frac{\left(1-\varepsilon_{w}\right)\left(1-\beta \varepsilon_{w}\right)}{\varepsilon_{w}(1+\chi \eta)}
$$

where $\varepsilon_{p} \in[0,1]$ and $\varepsilon_{w} \in[0,1]$ carry information regarding the frequency of price and wage adjustments, while $\theta>1$ and $\eta>1$ are the elasticities of demand for alternative varieties of

\footnotetext{
${ }^{4}$ For a detailed discussion of the model, refer to Woodford (2003, Chapter 3).
} 
goods and labor. ${ }^{5}$ The parameter $\chi>0$ measures the inverse of the Frisch (wage) elasticity of labor supply, and $\alpha \in(0,1)$ is the capital elasticity of output. ${ }^{6}$

Woodford (2003) demonstrates that (2) is simply a generalization of the standard New Keynesian Phillips curve that links inflation to the output gap and expected future inflation. Profit maximization ensures that firms select prices as a markup over a discounted stream of real marginal cost. In the event that wages are flexible, the average level of real marginal cost is positively related to variations in the output gap alone. Wage stickiness, however, implies that real marginal cost co-moves with deviations of both output and the real wage from their respective natural rates. When wages are perfectly flexible, $\varepsilon_{w}=0$ and the block given by (2) - (4) reduces to a single equation recognized as the conventional New Keynesian Phillips curve.

In order to generate more substantial policy tradeoffs, I follow Clarida, Galí, and Gertler (1999) by amending the supply equations with two additive disturbances. ${ }^{7}$ The terms $e_{\pi, t}$ and $e_{w, t}$ reflect "cost-push" shocks summarizing all exogenous variation in price and wage inflation not attributed to fluctuations in excess demand. ${ }^{8}$ For the following analysis, $e_{\pi, t}$ and $e_{w, t}$ are first-order autoregressive processes

$$
\begin{aligned}
e_{\pi, t} & =\rho_{\pi} e_{\pi, t-1}+u_{\pi, t} \\
e_{w, t} & =\rho_{w} e_{w, t-1}+u_{w, t}
\end{aligned}
$$

where $\rho_{\pi}, \rho_{w} \in[0,1)$ and $u_{\pi, t}$ and $u_{w, t}$ are independent, mean-zero innovations with standard

\footnotetext{
${ }^{5}$ Using the "Calvo" terminology, $\varepsilon_{p}\left(\varepsilon_{w}\right)$ corresponds to the fixed probability that a randomly selected firm (household) will be unable to optimally reset its price (wage) in any given period.

${ }^{6}$ The consequence of incorporating fixed capital manifests itself in the mapping between $\varepsilon_{p}$ and $\xi_{p}$. As illustrated by Woodford (2005), the absence of a rental market reduces the value of $\xi_{p}$ for any given frequency of price adjustment.

${ }^{7}$ Erceg et al. (2000) demonstrate that incorporating sticky wages creates an endogenous tradeoff between stabilizing inflation and the output gap. Nevertheless, supply shocks are included because the policy response under full commitment and discretion to fluctuations in $w_{t}^{n}$ alone are not very different.

${ }^{8}$ I assume that the incidence of supply-side shocks leaves the distortionless equilibrium undisturbed. For instance, the shocks could be the result of time variation in the markups as in Smets and Wouters (2003).
} 
deviations $\sigma_{\pi}$ and $\sigma_{w}$.

Finally, the model's equilibrium dynamics are determined in part by the stochastic properties of $w_{t}^{n}$ and $r_{t}^{n}$. Under flexible prices and wages, allocations depend entirely on shocks to preferences and technologies. To simplify the following exposition, a single productivity disturbance will constitute the only source of exogenous variation in $w_{t}^{n}$ and $r_{t}^{n}$. Denote $a_{t}$ the productivity shock assumed to obey the following autoregressive process:

$$
a_{t}=\rho_{a} a_{t-1}+u_{a, t}
$$

where $\rho_{a} \in[0,1)$ and $u_{a, t}$ is a mean-zero innovation with standard deviation $\sigma_{a}$. It follows that $w_{t}^{n}$ and $r_{t}^{n}$ can be expressed in terms of $a_{t}$ and the underlying structural coefficients as

$$
w_{t}^{n}=\left(\frac{\frac{\chi+\sigma}{1-\alpha}}{\frac{\alpha+\chi}{1-\alpha}+\sigma}\right) a_{t} \quad \text { and } \quad r_{t}^{n}=\left(\frac{-\sigma\left(\frac{1+\chi}{1-\alpha}\right)\left(1-\rho_{a}\right)}{\frac{\alpha+\chi}{1-\alpha}+\sigma}\right) a_{t} .
$$

Consequently, $w_{t}^{n}$ and $r_{t}^{n}$ inherit the same stochastic properties as $a_{t}$.

\subsection{The Social Loss Function}

The singular duty of monetary policy is to minimize the distortions in the allocation of goods and labor that result from the inability of firms and households to freely adjust individual prices and wages. A natural metric for evaluating the magnitude of these distortions is the household's utility function.

$$
\mathbb{W}_{t} \equiv U\left(C_{t}\right)-\int_{0}^{1} \nu\left(H_{t}(i)\right) d i
$$

$\mathbb{W}_{t}$ is an equally weighted average of household welfare, comprised of positive utility flows from consumption services $U\left(C_{t}\right)$ and negative utility flows from supplying labor $\nu\left(H_{t}(i)\right)$. Denote $\mathbb{W}_{t}^{n}$ the period welfare function consistent with perfectly flexible prices and wages. 
The central bank ranks alternative policies using a criterion that measures the expected deadweight loss $(\mathbb{L})$ associated with an equilibrium induced by a chosen policy relative to the frictionless equilibrium.

$$
\mathbb{L} \equiv-E_{0} \sum_{t=0}^{\infty} \beta^{t} \frac{\mathbb{W}_{t}-\mathbb{W}_{t}^{n}}{U_{c}(\bar{C}) \bar{C}}
$$

The welfare departures $\mathbb{W}_{t}-\mathbb{W}_{t}^{n}$ are scaled by $U_{c}(\bar{C}) \bar{C}$ in order to express loss as a fraction of steady-state consumption. Accordingly, $\mathbb{L}$ represents the equivalent variation associated with a given policy, the lump-sum increase in consumption required to make households indifferent between the realized allocations and those obtained in a flexible price and wage environment.

In order to evaluate loss using (1) - (4), I follow Rotemberg and Woodford (1997) and Erceg et al. (2000) by constructing a quadratic approximation of (9) around a zero-inflation steady state.

$$
\mathbb{L} \approx E_{0} \sum_{t=0}^{\infty} \beta^{t}\left\{\lambda_{\pi} \pi_{t}^{2}+\lambda_{w} \pi_{t}^{w^{2}}+\lambda_{x} x_{t}^{2}\right\}
$$

Equation (10) indicates that the welfare departures can be approximated up to second order by the cumulative effect on the second moments of price inflation, wage inflation, and the output gap. ${ }^{9} E_{0}$ is the mathematical expectations operator conditional on a particular value of the initial state vector observed prior to the implementation of policy. For the exercises that follow, I assume that at time zero all relevant state variables correspond to their nonstochastic steady state values and are thus invariant to changes in policy. This ensures that the economy begins from the same initial point regardless of the policy considered. ${ }^{10}$

The nonnegative coefficients $\left\{\lambda_{\pi}, \lambda_{w}, \lambda_{x}\right\}$ are preference weights that measure the strength

\footnotetext{
${ }^{9}$ The assumption of monopoly power implies that potential output is inefficiently low, and so (10) should include a positive target value for the output gap. I assume that it is the duty of fiscal policy to mitigate the steady-state distortions caused by imperfect competition, thereby avoiding unnecessary complications concerning an average inflation bias when the output gap target is positive.

${ }^{10} \mathrm{Kim}$, Kim, Schaumburg, and Sims (2003) have noted that the welfare ranking of alternative policies depends upon the value of the initial state vector. If instead it is taken as a random vector, then welfare depends on its assumed distribution function.
} 
in which the policymaker pursues each stabilization goal. The use of a utility-based welfare criterion places the following restrictions on the size of the policy weights:

$$
\begin{aligned}
& \lambda_{\pi}=\frac{\theta}{2 \xi_{p}} \\
& \lambda_{w}=\frac{\eta(1-\alpha)}{2 \xi_{w}} \\
& \lambda_{x}=\frac{1}{2}\left(\frac{\chi+\alpha}{1-\alpha}+\sigma\right)
\end{aligned}
$$

A potential criticism of the recent work by Jensen (2002), Walsh (2003), Vestin (2000), and Söderström (2005) is the failure to confront the relationship between the social loss function and the model of the economy. These authors stipulate an "ad hoc" objective function and then examine the impact of variations in the policy weights while holding the structural parameters fixed. By making the objectives of households, firms, and the central bank mutually consistent, I impose an unambiguous relationship between the policy weights and the structural parameters. For example, when the frequency of price changes falls, $\varepsilon_{p}$ rises and $\xi_{p}$ falls, increasing $\lambda_{\pi}$ while leaving $\lambda_{w}$ and $\lambda_{x}$ unchanged. Thus, increases in the average duration of price contracts weakens the policymaker's preference for stabilizing wage inflation and the output gap relative to price inflation. Similarly, when the frequency of wage adjustments falls, $\varepsilon_{w}$ rises and $\xi_{w}$ falls, causing $\lambda_{w}$ to rise. So in contrast, increasing the mean duration of wage contracts strengthens the policymaker's resolve for stabilizing wage inflation relative to the output gap and price inflation. ${ }^{11}$

\footnotetext{
${ }^{11}$ For a complete derivation of the welfare function, refer to Erceg et al. (2000) and Woodford (2003, Chapter 6).
} 


\section{Optimal Policy From a Timeless Perspective}

As a benchmark for the comparison of alternative targeting regimes under discretion, it is useful to identify the equilibrium process $\left\{\pi_{t}, \pi_{t}^{w}, x_{t}, w_{t}\right\}_{t=0}^{\infty}$ that minimizes (10) under commitment subject to the behavioral constraints given by $(2)-(4) .{ }^{12}$ The Lagrangian for this problem is

$$
\begin{aligned}
\mathcal{L}=\min _{\left\{x_{t}\right\}_{t=0}^{\infty}} E_{0} \sum_{t=0}^{\infty} \beta^{t} & \left\{\lambda_{\pi} \pi_{t}^{2}+\lambda_{w} \pi_{t}^{w^{2}}+\lambda_{x} x_{t}^{2}+2 v_{t}\left[w_{t}-w_{t-1}+\pi_{t}-\pi_{t}^{w}\right]\right. \\
& +2 \varphi_{\pi, t}\left[\pi_{t}-\beta \pi_{t+1}-\xi_{p}\left(\frac{\alpha}{1-\alpha}\right) x_{t}-\xi_{p}\left(w_{t}-w_{t}^{n}\right)-e_{\pi, t}\right] \\
& \left.+2 \varphi_{w, t}\left[\pi_{t}^{w}-\beta \pi_{t+1}^{w}-\xi_{w}\left(\frac{\chi}{1-\alpha}+\sigma\right) x_{t}+\xi_{w}\left(w_{t}-w_{t}^{n}\right)-e_{w, t}\right]\right\}
\end{aligned}
$$

where $\varphi_{\pi, t}, \varphi_{w, t}$, and $v_{t}$ are the Lagrange multipliers associated with constraints (2), (3), and (4), respectively.

Differentiating the Lagrangian delivers a system of first-order conditions

$$
\begin{aligned}
\lambda_{\pi} \pi_{t}+\varphi_{\pi, t}-\varphi_{\pi, t-1}+v_{t} & =0 \\
\lambda_{w} \pi_{t}^{w}+\varphi_{w, t}-\varphi_{w, t-1}-v_{t} & =0 \\
\lambda_{x} x_{t}-\xi_{p}\left(\frac{\alpha}{1-\alpha}\right) \varphi_{\pi, t}-\xi_{w}\left(\frac{\chi}{1-\alpha}+\sigma\right) \varphi_{w, t} & =0 \\
v_{t}-\xi_{p} \varphi_{\pi, t}+\xi_{w} \varphi_{w, t}-\beta E_{t} v_{t+1} & =0
\end{aligned}
$$

for any $t \geq 0$. The optimality requirements $(14)-(17)$, together with $(2)-(4)$ and the initial conditions $\varphi_{\pi,(-1)}=\varphi_{w,(-1)}=0$, fully characterize the optimal state-contingent solution $\left\{\pi_{t}, \pi_{t}^{w}, x_{t}, w_{t}, \varphi_{\pi, t}, \varphi_{w, t}, v_{t}\right\}_{t=0}^{\infty}$. The equilibrium, however, is not time consistent. Woodford (2003) demonstrates that there is an alternative concept of commitment generating the

\footnotetext{
${ }^{12}$ I treat the output gap as the policy instrument, and then subsequently use (1) to find the interest rate plan that is consistent with the optimal path of the output gap.
} 
optimal response to the exogenous shocks that also satisfies the principle of time consistency. Instead of imposing the boundary conditions $\varphi_{\pi,(-1)}=\varphi_{w,(-1)}=0$, imagine that $(14)-(17)$ hold for any $-\infty<t<\infty$. Woodford describes this notion of equilibrium as optimal from a "timeless perspective" because it forbids the policymaker from exploiting the existing stance of private sector expectations in the initial period.

To find such a policy, eliminate the Lagrange multipliers from (14) - (17). All of the information collapses to the following time-invariant criterion that involves only leads and lags of the variables in the loss function:

$$
\kappa\left(\lambda_{\pi} \xi_{p} \pi_{t}-\lambda_{w} \xi_{w} \pi_{t}^{w}\right)+\left(\xi_{p}+\xi_{w}\right) q_{t}+\left[q_{t}-q_{t-1}-\beta E_{t} q_{t+1}+\beta E_{t-1} q_{t}\right]=0
$$

where the variable $q_{t}$ satisfies

$$
q_{t}=\lambda_{\pi} \xi_{p}\left(\frac{\alpha}{1-\alpha}\right) \pi_{t}+\lambda_{w} \xi_{w}\left(\frac{\chi}{1-\alpha}+\sigma\right) \pi_{t}^{w}+\lambda_{x}\left(x_{t}-x_{t-1}\right)
$$

and $\kappa=\xi_{w}\left(\frac{\chi}{1-\alpha}+\sigma\right)-\xi_{p}\left(\frac{\alpha}{1-\alpha}\right)$. The joint equilibrium process $\left\{\pi_{t}, \pi_{t}^{w}, x_{t}, w_{t}, q_{t}\right\}_{t=-\infty}^{\infty}$ implied by (2) - (4) and (18) - (19) generates the desired state-contingent evolution characterized above.

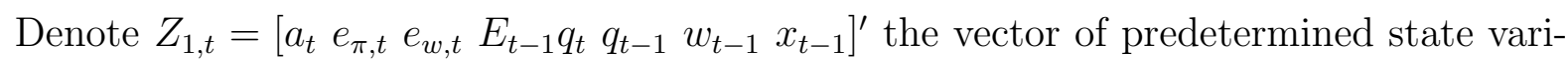
ables, $Z_{2, t}=\left[\begin{array}{llll}\pi_{t} & \pi_{t}^{w} & w_{t} & x_{t}\end{array} q_{t}\right]^{\prime}$ the vector of forward-looking variables, and $u_{t}=\left[u_{a, t} u_{\pi, t} u_{w, t}\right]^{\prime}$ the vector of innovations to the shocks contained in $Z_{1, t}$ with covariance matrix $\Sigma_{u}$. In compact notation, the system of expectational difference equations can be written as

$$
\Gamma\left[\begin{array}{c}
Z_{1, t+1} \\
E_{t} Z_{2, t+1}
\end{array}\right]=\Lambda\left[\begin{array}{c}
Z_{1, t} \\
Z_{2, t}
\end{array}\right]+\left[\begin{array}{c}
\Upsilon u_{t+1} \\
0
\end{array}\right]
$$

where $\Gamma$ and $\Lambda$ are matrices containing the various structural parameters and policy weights, 
and $\Upsilon$ is a $7 \times 3$ selector matrix. I seek a unique bounded solution to the system given by (20) of the form

$$
Z_{2, t}=\Phi Z_{1, t}
$$

where $\Phi$ is a matrix characterizing the linear mapping of the forward-looking variables into the space spanned by the predetermined variables. Because $\Gamma$ is singular by construction, I follow the technique expounded in Klein (2000) which uses the generalized Schur form to separate (20) into stable and unstable blocks of equations. Echoing the conditions in Blanchard and Kahn (1980), a unique bounded solution exists if the number of stable eigenvalues equals the number of predetermined variables. I verify numerically that the determinacy condition is satisfied for the various parameter configurations used in this paper.

To highlight the economy's dynamic properties under the optimal rule, Figure 1 plots the impulse response function to simultaneous shocks to $e_{\pi, t}$ and $e_{w, t} \cdot{ }^{13}$ In the aftermath of a joint shock to aggregate supply, the optimal policy response entails an immediate reduction (rise) in the output gap (interest rate) followed by a measured ascent (descent) back to its long-run target. In other words, monetary policy remains tight for several periods after the realization of the shocks. Woodford (1999) labels this characteristic of commitment "optimal monetary policy inertia." In a model with forward-looking agents, a credible promise to impart inertia into policy actions lowers private sector expectations of future inflation, thereby improving the current stabilization outcome. While $\pi_{t}$ and $\pi_{t}^{w}$ are positive upon impact, both variables overshoot their respective long-run target values and remain negative for a number of periods. The deflationary episodes cause the price level and the nominal wage to return to the same paths anticipated prior to the occurrence of the shocks. An optimal plan, therefore, generates stationary fluctuations in prices and wages following shocks to aggregate supply.

\footnotetext{
${ }^{13}$ Setting $\rho_{\pi}=\rho_{w}=0$ makes the "cost-push" disturbances purely transitory in this example.
} 
Figure 1: Dynamic Response To A Joint Cost-Push Shock
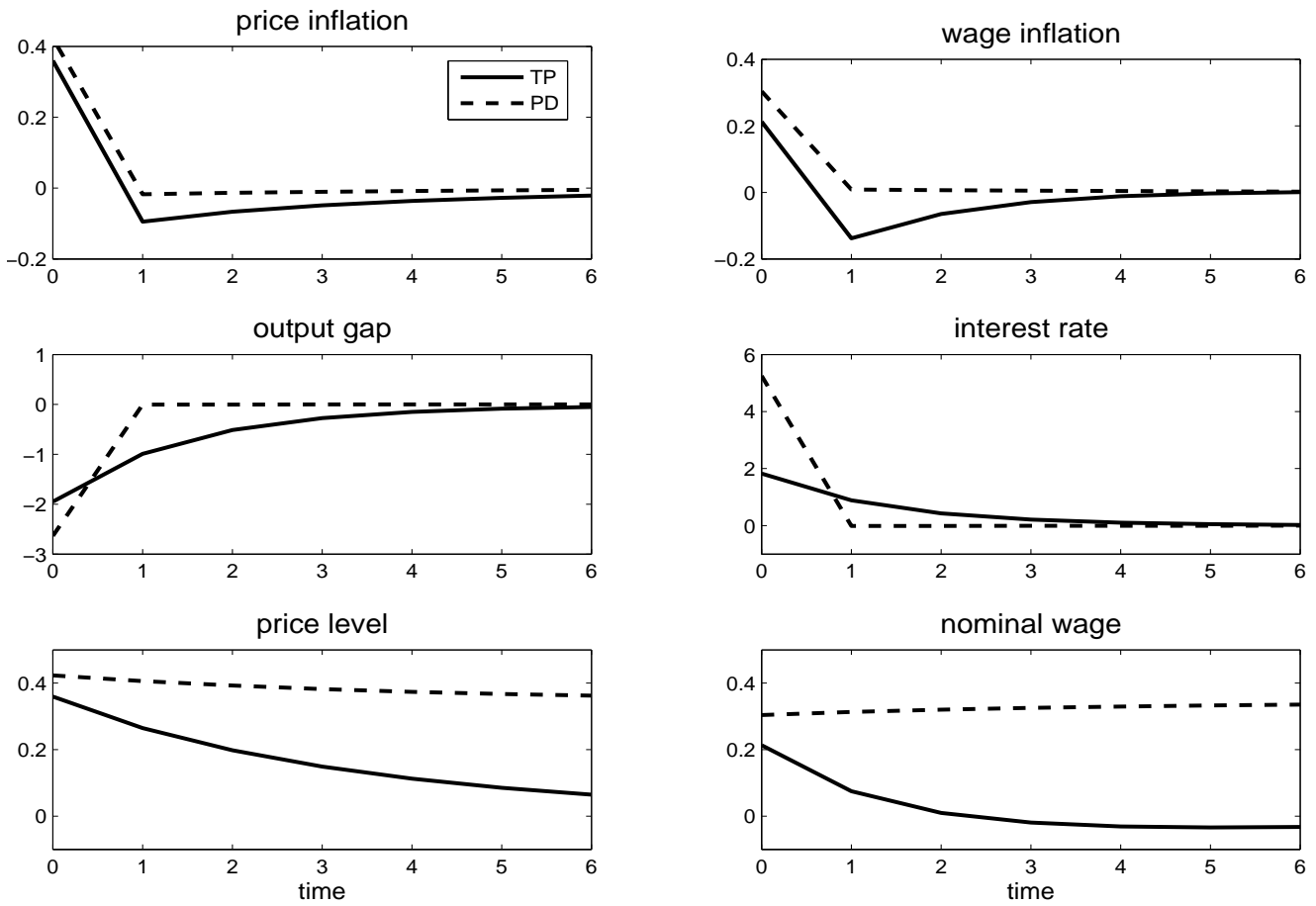

Note: Response to a simultaneous transitory shock to $e_{\pi, t}$ and $e_{w, t}, \mathbf{T P}$ - Timeless Perspective, PD - Pure Discretion

\section{Targeting Regimes Under Discretion}

I now shift focus to the central goal of this paper, the delegation of alternative targeting regimes to a central bank operating under discretion. Following Jensen (2002), a targeting regime is understood to be an "institutional setup" whereby the central bank minimizes an assigned loss function whose policy weight coefficients are preselected to insure the lowest possible value of social loss as measured by (10). ${ }^{14}$

The family of policy regimes are defined over a set of target variables that include $\pi_{t}, \pi_{t}^{w}$,

\footnotetext{
${ }^{14}$ The concept of delegation used here is closely related to what Svensson (1999a) calls a targeting rule, the selection of a particular loss function that specifies a set of target variables (stabilization goals) and corresponding policy weights.
} 
$x_{t}$, the price level $p_{t}$, and the nominal wage $n_{t}$. I nest each regime in a general loss function of the form

$$
\text { Loss }=E_{0} \sum_{t=0}^{\infty} \beta^{t}\left\{\left(1+f_{\pi}\right) \pi_{t}^{2}+\left(\tilde{\lambda}_{w}+f_{w}\right) \pi_{t}^{w^{2}}+\tilde{\lambda}_{x} x_{t}^{2}+g_{p} p_{t}^{2}+g_{n} n_{t}^{2}\right\}
$$

where $\tilde{\lambda}_{w}=\frac{\lambda_{w}}{\lambda_{\pi}}$ and $\tilde{\lambda}_{x}=\frac{\lambda_{x}}{\lambda_{\pi}}$ are the same coefficients appearing in (10) normalized by the weight on $\pi_{t}$. Because prices and wages are stationary under the timelessly optimal rule, a policymaker may find it desirable to make $p_{t}$ and $n_{t}$ explicit stabilization goals. The idea is that if the precommitment policy is not feasible, the central bank can mimic commitmentlike behavior by directing policy towards stabilizing the price level or the nominal wage. The loss function weights $\left\{f_{\pi}, f_{w}, g_{p}, g_{n}\right\}$ are chosen optimally to minimize (10) prior to the delegation of monetary policy. Each regime is demarcated by certain constraints placed on the values of the chosen weights.

The first regime is pure discretion (PD) in which case $f_{\pi}=f_{w}=g_{p}=g_{n}=0$. $\mathrm{PD}$ amounts to discretionary optimization of the social loss function because the target variables are identical to those in (10) and the weights are simply the normalized values of $\lambda_{\pi}, \lambda_{w}$, and $\lambda_{x}$. It provides a natural reference point for quantifying the gains from designing alternative targets.

The second regime is inflation targeting (IT) in which case the central bank directs policy toward stabilizing price and wage inflation by setting $f_{\pi} \in[-1, \infty), f_{w} \in\left[-\tilde{\lambda}_{w}, \infty\right)$, and $g_{p}=g_{n}=0$. Although the target variables coincide with the ones in (10), the weights assigned to these objectives may differ. Values of $f_{\pi}>0$ or $f_{w}>0$, for instance, correspond to the appointment of a "conservative central banker" in the sense of Rogoff (1985) because the policymaker places additional emphasis on attaining inflation stability relative to output gap stability.

Vestin (2000) argues that under certain conditions, a suitably designed price level target 
is equivalent to inflation targeting under commitment. In light of this finding, the third regime, price level targeting $(\mathrm{PT})$, requires that $g_{p} \in[0, \infty), f_{\pi}=-1, f_{w}=-\tilde{\lambda}_{w}$, and $g_{n}=0$. Under PT, the central bank directly pursues stabilization of only the price level and the output gap.

Due to the success of PT in some forward-looking models, I also explore the possible benefits of implementing an explicit wage target. The fourth regime, nominal wage targeting (WT), is defined as the case where $g_{n} \in[0, \infty), f_{\pi}=-1, f_{w}=-\tilde{\lambda}_{w}$, and $g_{p}=0$. Under WT, stability of the nominal wage and the output gap are the sole objectives of policy.

The fifth regime considered is called price and wage targeting (PWT), a combination policy where $g_{p} \in[0, \infty), g_{n} \in[0, \infty), f_{\pi}=-1$, and $f_{w}=-\tilde{\lambda}_{w}$. A PWT strategy seeks an optimum balance in price, nominal wage, and output gap stability. Clearly, PWT encompasses PT and WT as special cases. The combination policy serves primarily as an illustration of the gain from implementing joint price and wage targets. ${ }^{15}$

To solve for the equilibrium dynamics implied by discretionary optimization, cast the model into state-space form. First, rewrite the aggregate supply equations in terms of the price level and the nominal wage using the identities $\pi_{t}=p_{t}-p_{t-1}, \pi_{t}^{w}=n_{t}-n_{t-1}$, and $w_{t}=n_{t}-p_{t}$. Denote $X_{1, t}=\left[a_{t} e_{\pi, t} e_{w, t} p_{t-1} n_{t-1}\right]^{\prime}$ the vector of exogenous and endogenous predetermined variables and $X_{2, t}=\left[p_{t} n_{t}\right]^{\prime}$ the vector of forward-looking variables. Recall that $u_{t}=\left[\begin{array}{lll}u_{a, t} & u_{\pi, t} & u_{w, t}\end{array}\right]^{\prime}$ is the vector of innovations to the structural shocks contained in $X_{1, t}$. Again, it is convenient treat the output gap $x_{t}$ as the policy instrument. Next, stack the policy constraints in the following way:

$$
\left[\begin{array}{c}
X_{1, t+1} \\
\Omega E_{t} X_{2, t+1}
\end{array}\right]=A\left[\begin{array}{c}
X_{1, t} \\
X_{2, t}
\end{array}\right]+B x_{t}+\left[\begin{array}{c}
N u_{t+1} \\
0
\end{array}\right]
$$

\footnotetext{
${ }^{15}$ Each of the targeting regimes considered is "flexible" in the usual sense of the word because the policymaker values a certain degree of real stability as measured by variation in the output gap.
} 
where $\Omega, A$, and $B$ are matrices of structural parameters, and $N$ is a $5 \times 3$ selector matrix.

Similarly, denote $T_{t}=\left[\begin{array}{llll}\pi_{t} & \pi_{t}^{w} & x_{t} & p_{t} \\ n_{t}\end{array}\right]^{\prime}$ the vector of target variables. $T_{t}$ is related to the state vector and the policy instrument by the following linear relationship:

$$
T_{t}=C\left[\begin{array}{c}
X_{1, t} \\
X_{2, t}
\end{array}\right]+D x_{t}
$$

where

$$
C=\left[\begin{array}{ccccccc}
0 & 0 & 0 & -1 & 0 & 1 & 0 \\
0 & 0 & 0 & 0 & -1 & 0 & 1 \\
0 & 0 & 0 & 0 & 0 & 0 & 0 \\
0 & 0 & 0 & 0 & 0 & 1 & 0 \\
0 & 0 & 0 & 0 & 0 & 0 & 1
\end{array}\right] \text { and } D=\left[\begin{array}{c}
0 \\
0 \\
1 \\
0 \\
0
\end{array}\right]
$$

Reformulating (22) in terms of $T_{t}$, the central bank's loss function can be written as

$$
\text { Loss }=E_{0} \sum_{t=0}^{\infty} \beta^{t} T_{t}^{\prime} Q T_{t} \quad Q=\left[\begin{array}{cccccc}
1+f_{\pi} & 0 & 0 & 0 & 0 \\
0 & \tilde{\lambda}_{w}+f_{w} & 0 & 0 & 0 \\
0 & 0 & \tilde{\lambda}_{x} & 0 & 0 \\
0 & 0 & 0 & g_{p} & 0 \\
0 & 0 & 0 & 0 & g_{n}
\end{array}\right]
$$

where $Q$ is a diagonal matrix whose nonzero elements are the policy weights. The discretionary outcome corresponds to a Markov-perfect equilibrium in which the central bank reoptimizes (22) subject to (23) every period taking the expectations of households and firms as exogenous. ${ }^{16}$

To determine the weights characterizing an optimal regime, perform a numerical search ${ }^{16}$ Söderlind (1999) demonstrates how to perform the optimal control exercise when the constraints are forward-looking. 
over acceptable values of $\left\{f_{\pi}, f_{w}, g_{p}, g_{n}\right\}$. For a given set of weights corresponding to a particular regime, use the reduced-form solution to the model under discretion to calculate the asymptotic value of the social loss function (10). Continue searching over the allowable parameter space until social loss reaches a minimum.

\section{Comparative Regime Performance}

In this section I assess the welfare properties of the targeting regimes defined above. As the conclusions depend heavily on the chosen parameterization, I first discuss model calibration, using values consistent with recent empirical studies and then repeat the exercise for a broad range of values to demonstrate robustness.

\subsection{Model Calibration}

Of critical importance are the parameters governing the distributional properties of the structural shocks. Regarding the persistence and volatility of productivity shocks, I set $\sigma_{a}=0.007$ and $\rho_{a}=0.95$, identical to the values chosen by Cooley and Prescott (1995) and close to the ones used in the King and Rebelo (1999) survey of real business cycle models. Concerning the properties of the "cost-push" shocks, Smets and Wouters (2005) and Levin et al. (2005) estimate models that feature stochastic markups in goods and factor markets and conclude that wage markup shocks are more volatile than price markup shocks in U.S. data. Because there is no established consensus on this topic, however, I set $\sigma_{\pi}=\sigma_{w}=0.005$, imposing equal volatility of shocks to prices and wages. Initially, I fix $\rho_{\pi}=\rho_{w}=0$, but later relax this assumption to examine whether serial correlation alters regime performance.

I set $\beta=1.03^{-1 / 4}$ so that the model is consistent with an annualized mean real interest rate of 3 percent, and I fix $\alpha=1 / 3$, implying a steady-state share of labor income of approximately 67 percent. As for the parameters describing household preferences, I fix 
Table 1: Baseline Parameter Values

\begin{tabular}{crr}
\hline \hline Parameter & Description & Calibration \\
\hline$\beta$ & subjective discount factor & 0.99264 \\
$\alpha$ & capital elasticity of output & $1 / 3$ \\
$\sigma$ & inverse of the intertemporal elasticity of substitution & 2 \\
$\chi$ & inverse of the Frish elasticity of labor supply & 1 \\
$\eta$ & elasticity of demand for goods & 11 \\
$\varepsilon_{p}$ & elasticity of demand for labor & 11 \\
$\varepsilon_{w}$ & fraction of firms unable to reset prices & 0.6 \\
$\sigma_{a}$ & fraction of households unable to reset wages & 0.6 \\
$\sigma_{\pi}$ & standard deviation of technology shock & 0.007 \\
$\sigma_{w}$ & standard deviation of price inflation shock & 0.005 \\
$\rho_{a}$ & standard deviation of wage inflation shock & 0.005 \\
$\rho_{\pi}$ & serial correlation of the technology shock & 0.95 \\
$\rho_{w}$ & serial correlation of the price inflation shock & 0 \\
$\tilde{\lambda}_{w}$ & serial correlation of the wage inflation shock & 0 \\
$\tilde{\lambda}_{x}$ & optimal relative weight on wage inflation & 1.2308 \\
\hline \hline
\end{tabular}

$\sigma=2$ and $\chi=1$, implying an inverse of the intertemporal elasticity of substitution of 0.5 and a unitary Frish elasticity of labor supply, respectively. ${ }^{17}$

Concerning the parameters that govern price and wage-setting, I set $\theta=\eta=11$, implying a 10 percent steady-state markup in both product and factor markets and reasonably close to the empirical estimates reported by Rotemberg and Woodford (1997), Amato and Laubach (2003), and Christiano et al. (2005). Many of the same empirical studies, however, are largely inconclusive about the parameters characterizing the frequency of price and wage adjustments. Smets and Wouters (2005) and Levin et al. (2005), for instance, conclude that $\varepsilon_{p}$ and $\varepsilon_{w}$ span values of 0.75 to 0.9 , meaning that the average lifespan of a price or wage contract ranges from 4 to 10 quarters. Christiano et al. (2005), on the other hand, report values of $\varepsilon_{p}=0.6$ and $\varepsilon_{w}=0.64$, suggesting that while wage contracts last longer than price

\footnotetext{
${ }^{17}$ The chosen values for $\sigma$ and $\chi$ are well within the range of estimates provided by Smets and Wouters (2005) and Levin et al. (2005). Each set of authors use Bayesian methods to estimate the parameters of a stochastic dynamic general equilibrium model with the same utility structure as the one employed here.
} 
contracts on average, neither exceeds 3 quarters. Thus, I initially set $\varepsilon_{p}=\varepsilon_{w}=0.6$ and then subsequently vary both along the entire unit interval.

\subsection{Policy Evaluation}

The following tables report the welfare cost of deviating from the frictionless equilibrium, the optimal policy weight coefficients, and the standard deviations of $\left\{\pi_{t}, \pi_{t}^{w}, x_{t}\right\}$. Recall that $\mathbb{L}$ measures the onetime increase in consumption needed to make households indifferent between the realized allocations and those prevailing under flexible prices and wages. The welfare calculation actually reported in the tables corresponds to $(1-\beta) \mathbb{L}$, the equivalent increase in steady-state consumption sustained over an agent's lifetime. The leftmost column of numbers are those associated with the optimal timeless perspective (TP) policy.

\subsubsection{Baseline Configuration}

Table 2 reveals the principal inefficiencies of PD and IT. The implied standard deviations of $\left\{\pi_{t}, \pi_{t}^{w}, x_{t}\right\}$ are uniformly larger than their counterparts under TP, and the welfare cost associated with PD or IT is equivalent to a permanent loss of consumption of 0.529 percent relative to the frictionless equilibrium. To understand the results, return to Figure 1 which plots the dynamic response function for simultaneous shocks to $e_{\pi, t}$ and $e_{w, t}$ under the TP and PD policies. ${ }^{18} \mathrm{PD}$ is characterized by a single-period output gap (interest rate) contraction (expansion) following the joint "cost-push" shock and stands in sharp contrast to the inertial property observed under commitment. The absence of a sustained output gap reduction prevents $\pi_{t}$ and $\pi_{t}^{w}$ from mimicking the optimal overshooting behavior, generating nonstationary fluctuations in $p_{t}$ and $n_{t}$. As current outcomes depend on expectations of future price and wage inflation, a commitment to prolong the contraction partially insulates $\pi_{t}$ and

\footnotetext{
${ }^{18} \mathrm{I}$ do not display the response function associated with IT because it is essentially identical to PD under the baseline configuration.
} 
Table 2: Statistics for Baseline Parameter Values

\begin{tabular}{l|cccccc}
\hline \hline & TP & PD & IT & PT & WT & PWT \\
\hline Cons. Equiv. & 0.463 & 0.529 & 0.529 & 0.601 & 0.486 & 0.465 \\
Optimal $f_{\pi}$ & - & - & 0.103 & - & - & - \\
Optimal $f_{w}$ & - & - & -0.022 & - & - & - \\
Optimal $g_{p}$ & - & - & - & 0.129 & - & 1.028 \\
Optimal $g_{n}$ & - & - & - & - & 1.173 & 1.228 \\
S.d. of $\pi$ & 0.435 & 0.452 & 0.450 & 0.424 & 0.470 & 0.438 \\
S.d. of $\pi^{w}$ & 0.303 & 0.328 & 0.331 & 0.472 & 0.290 & 0.303 \\
S.d. of $x$ & 1.829 & 2.095 & 2.087 & 0.568 & 1.767 & 1.821 \\
\hline \hline
\end{tabular}

Note: The welfare costs and standard deviations are multiplied by 100 to express these statistics in percentage points. TP - timeless perspective, PD - pure discretion, IT - inflation targeting, PT - price targeting, WT - wage targeting, PWT - price and wage targeting, Cons. Equiv. - consumption equivalent or $(1-\beta) \mathbb{L}$.

$\pi_{t}^{w}$ from the destabilizing effect of the shocks in the impact period. Thus, policy tradeoffs deteriorate under PD and IT because a given level of price and wage inflation volatility requires a larger, albeit transitory, output gap contraction.

A comparison of columns three and four highlights the first basic conclusion of this paper, that PT is dominated by IT for a plausible calibration of the model. The welfare cost of $\mathrm{PT}$ is equivalent to a permanent reduction in consumption of 0.601 percent. Moreover, the standard deviations indicate that while PT achieves a lower volatility of price inflation than IT, it permits excess wage inflation volatility and over-stabilizes the output gap (considering the small relative weight on the output gap in the social loss function). The poor performance of price level targeting in the present model contrasts with the findings reported by Vestin (2000) who demonstrates that in a purely forward-looking model with a traditional Calvostyle Phillips curve, commitment to an inflation target is equivalent to price level targeting under discretion for an appropriately chosen policy weight. ${ }^{19}$ Perhaps more surprising, the same result deviates from one of the primary conclusions reached by Erceg et al. (2000), that interest rate rules responding to fluctuations in price inflation and the output gap alone

\footnotetext{
${ }^{19}$ Walsh (2003) reaffirms this conclusion by showing that price level targeting unambiguously yields the best outcome when the inflation process features little or no intrinsic persistence.
} 
perform nearly as well as the fully optimal policy. Because the models are structurally similar (the main difference lies in the treatment of capital), the likely source of the conflicting results is the inclusion of "cost-push" shocks in the present model.

As noted by Vestin (2000), the success of a price level target in forward-looking models comes from the ability to harness expectations in such a way as to prevent excess inflation volatility. Because the price level is persistent, the central bank's optimal response to an inflationary shock is a sustained contraction of the output gap, echoing the policy behavior observed under precommitment to an inflation target. The anticipation of this pattern of conduct by the private sector tapers inflation expectations, improving the current stabilization outcome. The left panel of Figure 2 illustrates that the same mechanism is at work in the present model. PT calls for a persistent output gap contraction in the face of a shock to $e_{\pi, t}$, generating an inflation response nearly identical to the one induced by the TP policy.

Evidently, the weakness of PT is the high volatility of $\pi_{t}^{w}$ that comes with it, a reflection of the inability to mitigate costly individual wage dispersion. ${ }^{20}$ Inspection of the model reveals that targeting the price level insulates $\pi_{t}^{w}$ from shocks to $e_{w, t}$ only to the extent that those shocks are transmitted to prices via their effect on the wage component of marginal cost. Under the baseline calibration, the contemporaneous impact of $n_{t}$ on $p_{t}$ is quantitatively small $\left(\xi_{p} \approx 0.041\right)$. Consequently, the recommended output gap adjustment following a shock to $e_{w, t}$ under PT is small, as illustrated in the right panel of Figure 2. The result is a much larger effect on $\pi_{t}^{w}$ upon impact. Thus, the benefit of price level targeting identified by Vestin (2000), namely, the inertial characteristic of policy directed towards inflationary shocks, is not sufficient to guarantee good performance in a model with nominal rigidities and "cost-push" disturbances in two different sectors.

The fifth column exemplifies the second major result of this paper, that a policy designed

\footnotetext{
${ }^{20}$ Erceg et al. (2000) demonstrate that the cross-sectional dispersion in wages is positively related to the variance of aggregate wage inflation.
} 
Figure 2: Dynamic Response To Each Cost-Push Shock
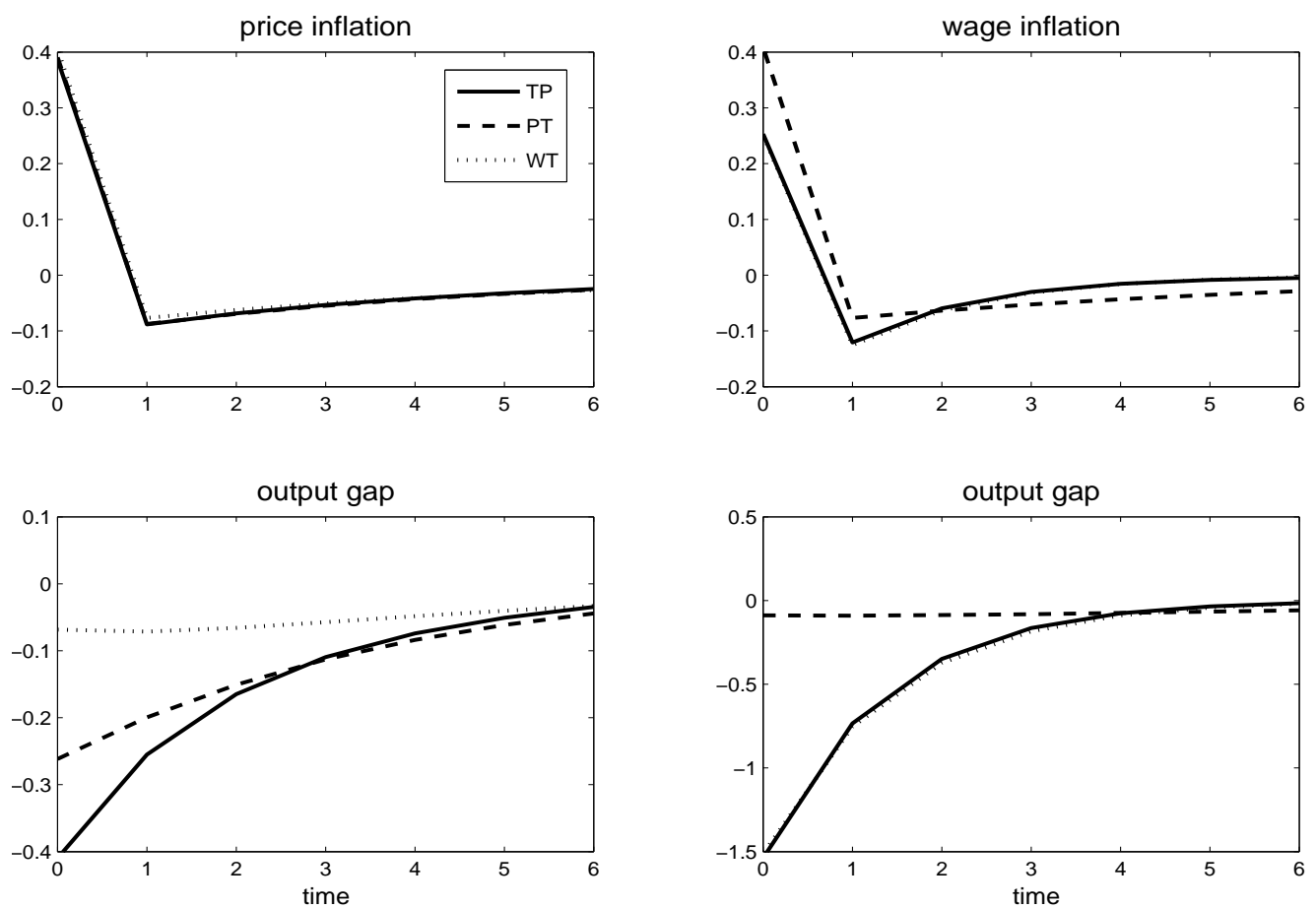

Note: Left Panel - response to a transitory $e_{\pi, t}$ shock, Right Panel - response to a transitory $e_{w, t}$ shock, TP - Timeless Perspective, PT - Price Targeting, WT - Wage Targeting.

to stabilize the nominal wage delivers a more favorable outcome than either a price level or inflation targeting policy. In contrast to PT and IT, the welfare cost of WT is commensurate with a sustained drop in consumption of 0.486 percent relative to the frictionless equilibrium. Additionally, the standard deviations indicate that while WT generates a mildly inefficient volatility of price inflation, the implied variance of wage inflation is nearly optimal, and unlike PT, does not over-stabilize the output gap. Interestingly, our results mirror the ones obtained by Canzoneri et al. (2004) and Levin et al. (2005), albeit in a somewhat different policy environment. ${ }^{21}$ Both sets of authors maximize welfare by searching over

\footnotetext{
${ }^{21}$ Mankiw and Reis (2003) report a similar finding using a micro-founded model with informational rigidities by showing that the optimal weight in a "stability price index" places a large emphasis on the level of nominal wages.
} 
the coefficients of a simple feedback rule for the nominal interest rate and conclude that a parsimonious rule responding to wage inflation alone nearly replicates the outcome under a fully optimal commitment policy.

To my knowledge, the welfare gains under WT prevail for two reasons. One, for the baseline configuration, $\frac{\lambda_{w}}{\lambda_{\pi}} \approx 1.23$, signaling that wage stability is moderately more important than price stability. The implication is that the variance of $\pi_{t}^{w}$ should be smaller than the variance of $\pi_{t}$ under an optimal policy as evidenced by the standard deviations under TP. Two, WT entails a larger cumulative policy response than PT in the aftermath of "costpush" shocks, improving the volatility tradeoff between $\pi_{t}, \pi_{t}^{w}$, and $x_{t}$. A discretionary central banker assigned the goals of stabilizing $p_{t}$ or $n_{t}$ on the one hand and $x_{t}$ on the other will pursue a "lean against the wind" policy in the face of supply shocks. The size of the contraction depends positively on the benefit from an incremental reduction of prices or wages per unit of output loss, or equivalently, on the magnitude of the output gap elasticity of inflation (i.e., the slope of the Phillips curve). ${ }^{22}$ For the baseline parameterization, the output gap elasticity of $\pi_{t}^{w}(.079)$ is greater than the corresponding elasticity of $\pi_{t}(.021)$, implying that the policymaker should, under WT, pursue wage stability more aggressively than price stability under PT. This property is also reflected in the fact that the optimal value of $g_{n}$ is considerably larger than that of $g_{p}\left(\frac{g_{n}}{g_{p}}=9.09\right)$.

Why is the more contractive nature of WT welfare enhancing? The model features intrinsic wage persistence, enabling transitory shocks to have lingering effects on wages. Thus, like PT, WT requires an inertial response of the output gap to "cost-push" shocks. A more hawkish position automatically reduces expectations of future wages and, to some extent, future prices as variations in $p_{t}$ impact $n_{t}$ through its effect on the real wage gap in (3). The ability to efficiently maneuver market expectations enables WT to impart a more

\footnotetext{
${ }^{22}$ The coefficient $\xi_{p}\left(\frac{\alpha}{1-\alpha}\right)$ measures the output gap elasticity of price inflation while $\xi_{w}\left(\frac{\chi}{1-\alpha}+\sigma\right)$ represents the output gap elasticity of wage inflation.
} 
collective restraining effect on price and wage inflation than PT. Figure 2 reinforces the concept graphically. WT calls for a sharp and persistent decline in the output gap following a shock to $e_{w, t}$. The subsequent response of wage inflation is practically equivalent to the efficient response under TP. Alternatively, the contraction observed under PT is small, and consequently, the rise in wage inflation is too severe. In response to an $e_{\pi, t}$ shock, WT recommends a small reduction in the output gap, but one that persists for several periods. Although the magnitude of the adjustment is not large, the mere understanding by the public that the central bank will aggressively counteract shocks to wages lowers expected future price inflation, thereby stabilizing current price inflation. In fact, Figure 2 demonstrates that the dynamic response of price inflation in the aftermath of a shock to $e_{\pi, t}$ under WT is nearly identical to the path implied by the TP policy. The fundamental reason is that WT makes better use of private sector expectations than PT to shoulder part of the task of stabilization.

The sixth column of Table 2 illustrates the last major result of this paper, that the combination PWT regime outperforms all others, nearly replicating the equilibrium attainable under the TP policy. The welfare cost associated with PWT is tantamount to a permanent decline in consumption of only 0.465 percent and virtually identical to the corresponding value under TP. On this point, Vestin (2000) concludes that a suitably designed price level target can exactly replicate the precommitment solution provided the "cost-push" shock is serially uncorrelated. Interestingly, the findings reported here suggest that this property does not extend symmetrically to a model with sticky prices in both goods and labor markets. A policymaker cannot in general duplicate the timeless perspective by delegating optimally chosen price and wage targets. Regardless, PWT appears to be a pragmatic way of reaping the benefits of policy inertia in a situation where the central bank must act in a discretionary manner. Instead of having to convey to the public a complicated targeting criterion like (18), the policymaker can perform the simpler task of assigning the optimal price and wage targets 
Table 3: Statistics For Persistent Supply Shocks

\begin{tabular}{l|cccccc}
\hline \hline & TP & PD & IT & PT & WT & PWT \\
\hline Cons. Equiv. & 2.403 & 3.335 & 2.842 & 3.585 & 2.633 & 2.432 \\
Optimal $f_{\pi}$ & - & - & 2.028 & - & - & - \\
Optimal $f_{w}$ & - & - & 3.174 & - & - & - \\
Optimal $g_{p}$ & - & - & - & 0.192 & - & 0.525 \\
Optimal $g_{n}$ & - & - & - & - & 0.615 & 0.619 \\
S.d. of $\pi$ & 1.016 & 1.174 & 1.066 & 0.924 & 1.164 & 1.029 \\
S.d. of $\pi^{w}$ & 0.524 & 0.771 & 0.419 & 1.160 & 0.423 & 0.518 \\
S.d. of $x$ & 5.613 & 5.420 & 7.391 & 4.041 & 5.445 & 5.636 \\
\hline \hline
\end{tabular}

Note: Statistics calculated for $\rho_{\pi}=\rho_{w}=0.7$.

to an otherwise independent central bank.

\subsubsection{Persistent Supply Shocks}

I now repeat the analysis for the case of serially correlated supply shocks by setting $\rho_{\pi}=$ $\rho_{w}=0.7$. Table 3 shows that the difference between IT and PD is no longer trivial. The welfare cost of IT is equivalent to a permanent drop in consumption of approximately 2.8 percent while the same calculation for PD exceeds 3.3 percent. In addition, a significant rise in the policy weights $\left(f_{\pi}=2.028\right.$ and $\left.f_{w}=3.174\right)$ is indicative of a much more conservative stance towards stabilizing price and wage inflation relative to the output gap. Now that shocks to $e_{\pi, t}$ and $e_{w, t}$ have lasting effects on $\pi_{t}$ and $\pi_{t}^{w}$, the prospect of a more favorable inflation-output gap variance tradeoff increases under a conservative policy by way of the stabilizing effects of expectations.

Because the addition of serial correlation increases the unconditional variances of $e_{\pi, t}$ and $e_{w, t}$, the consumption cost rises for all policies relative to the baseline calibration. Nevertheless, this modification has little impact on the comparative ranking among all policies for the same reasons discussed above. Due to the inability to offset fluctuations in $\pi_{t}^{w}$, PT remains inferior to IT, generating a welfare cost equivalent to a sustained reduction in consumption 
Table 4: Statistics For Large Price Shocks

\begin{tabular}{l|cccccc}
\hline \hline & TP & PD & IT & PT & WT & PWT \\
\hline Cons. Equiv. & 3.967 & 4.200 & 4.137 & 4.071 & 4.076 & 3.935 \\
Optimal $f_{\pi}$ & - & - & -0.419 & - & - & - \\
Optimal $f_{w}$ & - & - & 0.758 & - & - & - \\
Optimal $g_{p}$ & - & - & - & 0.177 & - & 0.822 \\
Optimal $g_{n}$ & - & - & - & - & 1.550 & 1.019 \\
S.d. of $\pi$ & 1.650 & 1.690 & 1.701 & 1.650 & 1.717 & 1.652 \\
S.d. of $\pi^{w}$ & 0.354 & 0.383 & 0.296 & 0.511 & 0.273 & 0.353 \\
S.d. of $x$ & 2.753 & 3.249 & 3.130 & 1.976 & 2.083 & 2.734 \\
\hline \hline
\end{tabular}

Note: Statistics calculated for $\sigma_{\pi}=0.02$.

exceeding 3.5 percent. The WT regime, on the other hand, dominates PT and IT, leading to a permanent consumption loss of only 2.633 percent. Finally, the joint PWT regime is again remarkably efficient, manufacturing a welfare cost equivalent to a permanent drop in consumption of 2.432 percent, only 0.029 percent more than the corresponding cost under TP.

\subsubsection{Larger Variance of Price Shocks}

I now investigate the consequences of changing the relative magnitudes of the supply shocks. The figures presented in Table 4 are calculated under the assumption that shocks to $e_{\pi, t}$ are four times the size of shocks to $e_{w, t}$ by resetting $\sigma_{\pi}=0.02$. In the absence of serial correlation, it is not surprising that IT only moderately outperforms PD. In contrast to earlier findings, however, it appears that PT dominates WT as a means of stabilizing $\left\{\pi_{t}, \pi_{t}^{w}, x_{t}\right\}$. Now that the variance of $\pi_{t}$ represents by far the largest contributor to social loss, PT is naturally the preferred regime. Strikingly, the differences are marginal at best (moving from WT to $\mathrm{PT}$ is equivalent to a permanent increase in consumption of only 0.005 percent), indicating that shocks to prices would have to be unusually large relative to wage shocks for PT to measurably outperform WT. Lastly, the dominance of PWT seems robust to changes in the 
relative magnitude of "cost-push" shocks, as the welfare departure from TP amounts to a mere 0.032 percent of consumption.

\subsection{Sensitivity Analysis}

To insure that the conclusions are not overly sensitive to the chosen calibration, I repeat the analysis for alternative values of the structural parameters. The following diagrams plot the welfare departure of each targeting regime from the timeless perspective policy by varying $\left\{\varepsilon_{p}, \varepsilon_{w}, \sigma, \chi, \alpha\right\}$ within a neighborhood encompassing the baseline values. For each graph, the welfare departures are expressed as a fraction of the welfare cost under the timeless perspective. In other words, for regime $i$, I plot the function

$$
\phi^{i}\left(\varepsilon_{p}, \varepsilon_{w}, \sigma, \chi, \alpha\right)=\frac{\mathbb{L}^{i}-\mathbb{L}^{\mathrm{TP}}}{\mathbb{L}^{\mathrm{TP}}} \times 100
$$

where $i$ is an element of the set $\Psi=\{\mathrm{PD}, \mathrm{IT}, \mathrm{PT}, \mathrm{WT}, \mathrm{PWT}\}$. For any $i, j \in \Psi$, regime $i$ dominates regime $j$ for a given set of parameter values if and only if $\phi^{i}<\phi^{j}$.

The left panel of Figure 3 shows how the welfare departures vary when altering $\varepsilon_{p}$ from zero (flexible prices) to unity (fixed prices). Despite the ability to impart inertia, PT performs worse than IT and PD for a wide range of plausible values. Targeting prices, however, becomes a relatively more efficient policy as prices become stickier. As the frequency of

price adjustment falls, the output gap elasticity of price inflation $\xi_{p}\left(\frac{\alpha}{1-\alpha}\right)$ falls (because $\left.\xi_{p}^{\prime}\left(\varepsilon_{p}\right)<0\right)$. Consequently, IT requires an increasingly aggressive response of $x_{t}$ to attain a given level of inflation stability because it prescribes only a one-period contraction in the aftermath of a transitory price shock. PT, on the other hand, requires a multi-period contraction because the same shock has an inertial effect on the price level. Thus, when prices are very sticky, the ability to distribute "policy medicine" in smaller doses over a longer horizon becomes more valuable as it reduces the variability of both inflation and the 
Figure 3: Welfare Deviations $(\phi)$ For Calvo Parameters
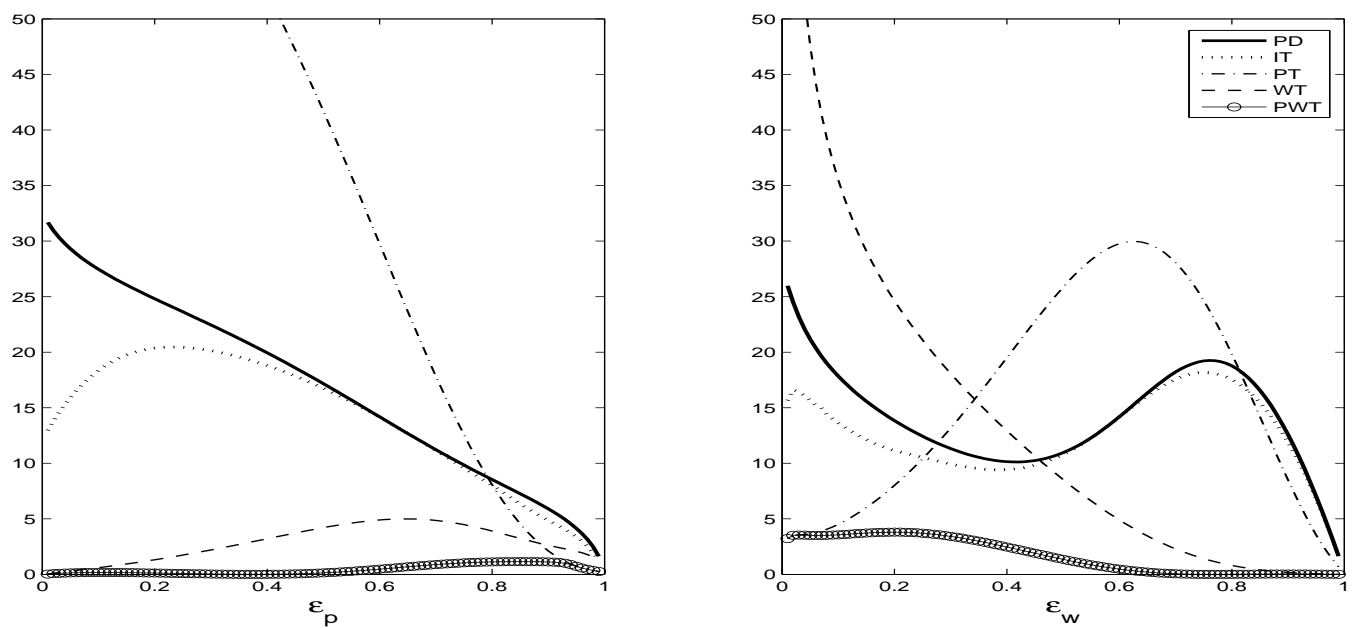

Note: As one structural parameter is varied, all others are held fixed at their baseline values. Optimal policy weights are recomputed for each regime and for all values of the parameter under examination. Pure Discretion (solid line), Inflation Targeting (dotted line), Price Targeting (dash-dotted line), Wage Targeting (dashed line), Price and Wage Targeting (solid line with circles).

output gap by harnessing the stabilizing effects of expectations.

The diagram also reaffirms the central argument concerning the effectiveness of wage targeting. For $\varepsilon_{p}<0.88$, WT strictly dominates PT. As prices become stickier, however, the relative importance of stabilizing $\pi_{t}$ increases (because $\lambda_{\pi}^{\prime}\left(\varepsilon_{p}\right)=-\frac{\theta}{2 \xi_{p}^{2}} \xi_{p}^{\prime}\left(\varepsilon_{p}\right)>0$ ). Only when price stability becomes the principal focus of monetary policy will PT outperform WT $\left(\frac{\lambda_{w}}{\lambda_{\pi}}=.079\right.$ for $\left.\varepsilon_{p}=.88\right)$. In fact, the figure suggests that if the mean duration of wage contracts is 2.5 quarters $\left(\varepsilon_{w}=0.6\right)$, the average price contract must endure for a term of at least 2 years before PT outperforms WT. Surprisingly, even when prices are very sticky, the welfare difference between the two policies is minimal. The reason why is due to the opposing effect increases in $\varepsilon_{p}$ have on the slope of the Phillips curve $\xi_{p}\left(\frac{\alpha}{1-\alpha}\right)$. Because $\xi_{p}^{\prime}\left(\varepsilon_{p}\right)<0$, the inflation-output gap variance tradeoff deteriorates sharply under PT as the frequency of price adjustment falls. This partially offsets the added benefit of targeting prices when price 
stability becomes the primary goal of monetary policy.

Lastly, PWT very nearly replicates the TP policy for all values of $\varepsilon_{p}$, effectively eliminating the "stabilization bias" of discretionary optimization. For $\varepsilon_{p} \in[0.11,0.91]$, it is optimal to mandate joint price and wage targets; however, PWT is equivalent to PT when $\varepsilon_{p}>0.91$ and equivalent to WT when $\varepsilon_{p}<0.11$.

The right panel of Figure 3 illustrates how the welfare departures vary in response to changes in $\varepsilon_{w}$ from zero (flexible wages) to unity (fixed wages). For $\varepsilon_{w} \in[0.27,0.83]$, IT dominates PT. Like the previous illustration, PT outperforms IT for values beyond the upper bound of this interval because the output gap elasticity of wage inflation $\xi_{w}\left(\frac{\chi}{1-\alpha}+\sigma\right)$ falls as $\varepsilon_{w}$ rises $\left(\xi_{w}^{\prime}\left(\varepsilon_{w}\right)<0\right)$, handicapping the non-inertial policies. In contrast to variations in $\varepsilon_{p}$, however, IT does not uniformly outperform PT for small values of $\varepsilon_{w}$. As wages become more flexible, the goal of price stability dominates (because $\lambda_{w}^{\prime}\left(\varepsilon_{w}\right)=-\frac{\eta(1-\alpha)}{2 \xi_{w}^{2}} \xi_{w}^{\prime}\left(\varepsilon_{w}\right)>0$ ). In the limiting case in which wages are completely flexible $\left(\varepsilon_{w} \rightarrow 0\right)$, a suitably chosen price level target can fully replicate the precommitment solution.

The dominance of WT over PT is remarkably robust to variations in $\varepsilon_{w}$. Only when wages become relatively more flexible than prices $\left(\varepsilon_{w}<0.35\right)$, signaling a diminished weight on $\pi_{t}^{w}$ in the social loss function $\left(\frac{\lambda_{w}}{\lambda_{\pi}}=.274\right.$ for $\left.\varepsilon_{w}=.35\right)$, does PT deliver a better stabilization outcome than WT. To further highlight the regularity with which WT outperforms PT, I compare the welfare cost under both policies for all possible combinations of $\varepsilon_{w}$ and $\varepsilon_{p}$. Figure 4 is the contour version of a 3-dimensional graph plotting the welfare deviations of WT from PT, expressed as a percentage of the loss accrued under WT. To be precise, I plot a contour map of the function

$$
\psi\left(\varepsilon_{w}, \varepsilon_{p}\right)=\frac{\mathbb{L}^{\mathrm{PT}}-\mathbb{L}^{\mathrm{WT}}}{\mathbb{L}^{\mathrm{WT}}} \times 100
$$

in which case positive entries on the map represent those $\left(\varepsilon_{w}, \varepsilon_{p}\right)$ combinations where WT 
Figure 4: Welfare Deviations $(\psi)$ For Calvo Parameters

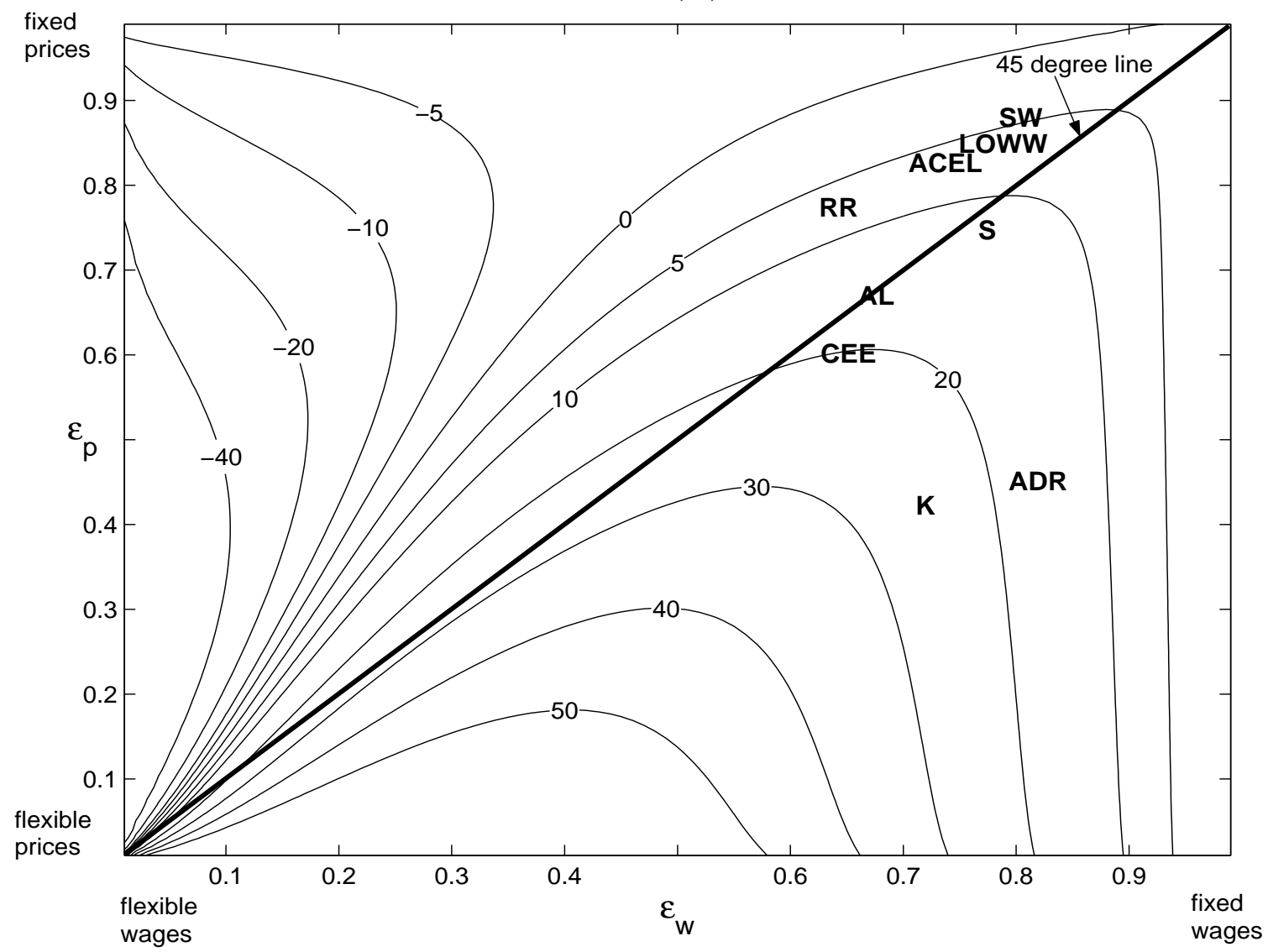

Note: Each axis is divided into 99 equally spaced grid points ranging from .01 to .99 . For every $\left(\varepsilon_{w}, \varepsilon_{p}\right)$ pair, the optimal weights are computed under PT and WT and the corresponding value of $\psi$ is recorded. CEE - Christiano et al. (2005), AL - Amato and Laubach (2003), ACEL - Altig et al. (2005), S - Sbordone (2004), RR - Rabanal and Rubio-Ramírez (2005), LOWW - Levin et al. (2005), SW - Smets and Wouters (2005), K - Kim (2003), ADR - Ambler, Dib, and Rebei (2004).

outperforms PT. A number of conclusions can be drawn from the figure. First, for every point below the 45 degree line (points where $\varepsilon_{w}>\varepsilon_{p}$ ), WT unambiguously dominates PT, indicating that a suitably designed wage target offsets more of the distortions engendered by sticky prices and wages provided the average duration of wage contracts are at least as long as price contracts. Second, for those combinations implying that wage adjustments occur at a moderately higher frequency than price adjustments (points just north of the 45 degree line), WT continues to perform as well or better than PT. A survey of recent empirical 
work reveals that formal estimates of $\varepsilon_{w}$ and $\varepsilon_{p}$ tend to bisect the 45 degree line in the upper right quadrant, implying that while contract renegotiations are somewhat infrequent for both prices and wages, the question of which is stickier is debatable. Interestingly, for any of those estimates, the corresponding welfare cost under PT exceeds the cost under WT by as little as 5 percent but as much as 25 percent in the present model. Lastly, PT leads to sizeable gains relative to WT, but only in the unlikely event that wages are almost fully flexible.

The left panel of Figure 5 graphs the welfare departures for alternative values of $\sigma$, the inverse of the intertemporal elasticity of substitution. A number of principle conclusions still hold. First, despite the ability to impart policy inertia, PT is dominated by PD and IT for a broad range of plausible values. ${ }^{23}$ In fact, the relative performance of PT deteriorates sharply as $\sigma$ rises, or as households become increasingly unwilling to alter consumption plans in response to changes in the real interest rate. Second, WT unambiguously outperforms PT and IT, generating a consumption cost that exceeds the TP cost by roughly 5 percent for all $\sigma \in[1,5]$. The uniform strength of WT is due to the precise way in which $\sigma$ enters the structural model. While $\sigma$ is positively related to the output gap elasticity of wage inflation $\xi_{w}\left(\frac{\chi}{1-\alpha}+\sigma\right)$, it has no direct impact on the corresponding elasticity of price inflation. Increasing $\sigma$, therefore, serves only to improve the inflation-output gap variance tradeoff under WT. On this point, Galí, Gertler, and López-Salido (2002) argue that direct estimates of the intertemporal elasticity of substitution $(1 / \sigma)$ typically vary between 0.1 and 0.3 using either micro-level or macro-level data. Thus, an empirically motivated value for $\sigma$ should fall somewhere on the interval $[3.33,10]$. The results reported here indicate that expanding the set of allowable values for $\sigma$ along these dimensions would amplify the already sizeable advantages of WT relative to PT.

The right panel of Figure 5 charts the relationship between $\phi$ and values of $\chi$ along the

\footnotetext{
${ }^{23} \mathrm{IT}$ is difficult to distinguish because it is practically equivalent to $\mathrm{PD}$ for $\sigma \in[1,5]$.
} 
Figure 5: Welfare Deviations $(\phi)$ For Utility Parameters
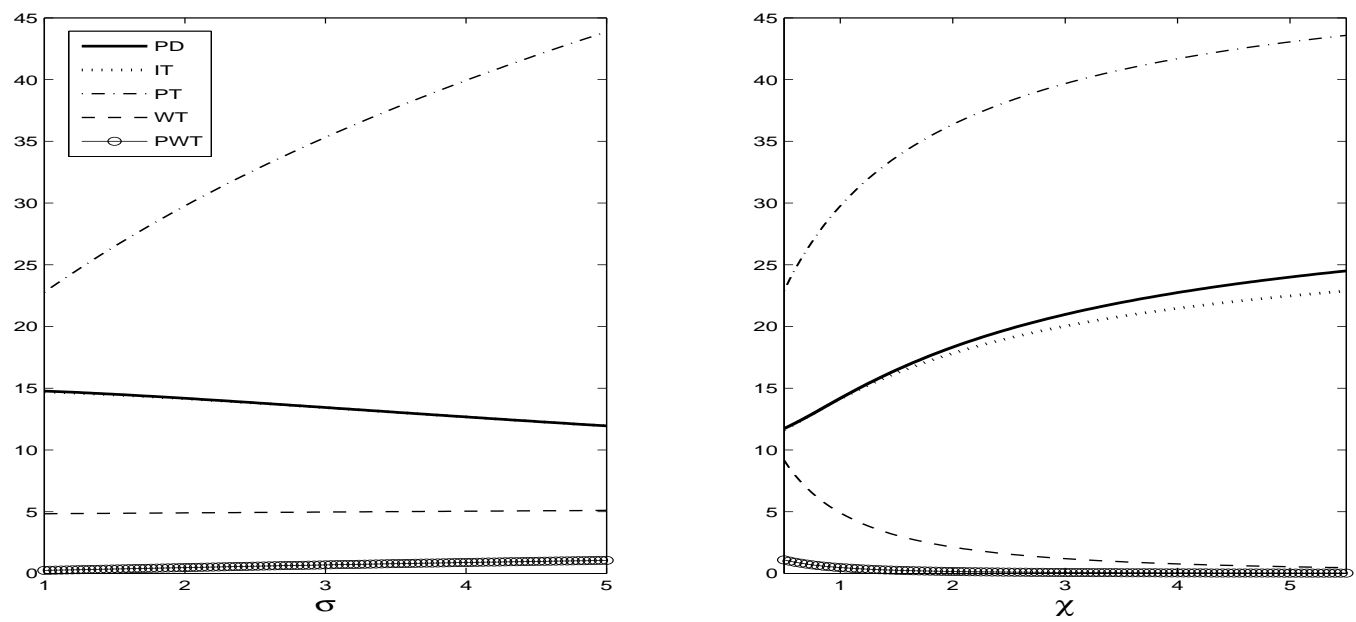

interval $[0.5,5.5]$. Shadowing the conclusions drawn for variations in $\sigma$, the results suggest that changes in the labor supply elasticity term have little effect on the comparative performance of PT to IT. In addition, increases in $\chi$ aggravate the weaknesses of PT while closing the gap between WT and TP. Unlike the results depicted in the left panel, however, the nearly optimal performance of WT is an artifact of the relationship between $\chi$ and $\lambda_{w}$. Increases in $\chi$ actually diminish the size of the output gap elasticity of wage inflation (because $\frac{\xi_{w}}{1-\alpha}+\left(\frac{\chi}{1-\alpha}+\sigma\right) \xi_{w}^{\prime}(\chi)<0$ ), strengthening the case for PT relative to WT. At the same time, however, increases in $\chi$ elevate the importance of wage stability (because $\left.\lambda_{w}^{\prime}(\chi)=-\frac{\eta(1-\alpha)}{2 \xi_{w}^{2}} \xi_{w}^{\prime}(\chi)>0\right)$, magnifying the advantages of WT. Evidently, the latter effect outweighs the former. Estimates of the wage elasticity of labor supply typically place $\chi$ in the range of 3 to 20 , so the baseline value $\chi=1$ perhaps understates the salutary properties of $\mathrm{WT}^{24}$

I conclude this section by examining the implications of adjusting $\alpha$, the capital elasticity of output, along the interval $[0.15,0.5]$. The results depicted in Figure 6 share a number of

\footnotetext{
${ }^{24}$ See Galí, Gertler, and López-Salido (2002) for a discussion.
} 
Figure 6: Welfare Deviations $(\phi)$ For Capital Elasticity Parameter

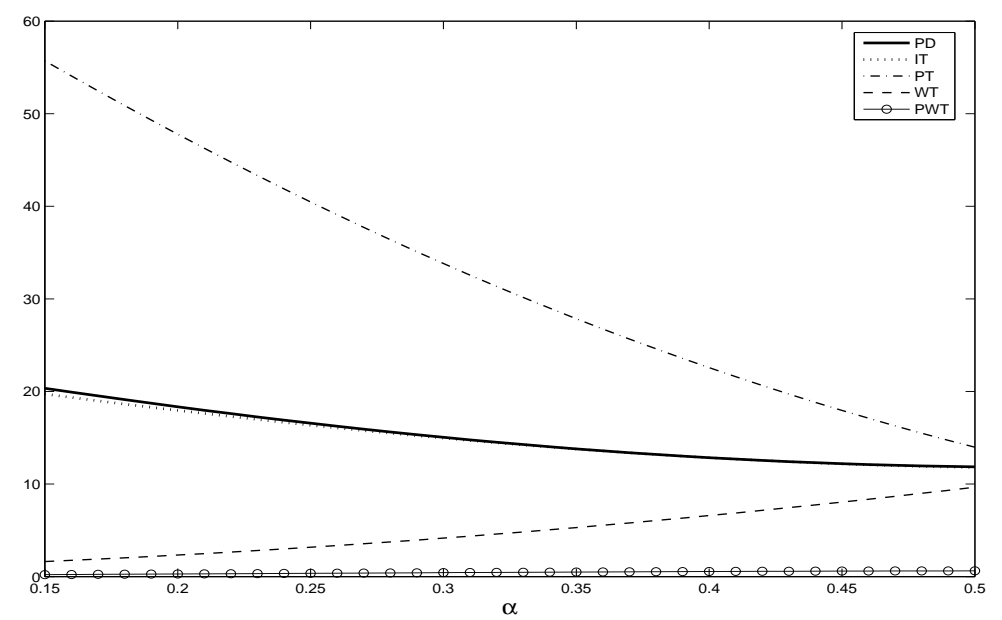

similarities with Figure 5, and so I choose not to comment on them any further. Instead, I concentrate on one key difference about the relationship between PT and WT. As illustrated in the figure, the performance of WT diminishes sharply relative to PT as $\alpha$ rises. Because the output gap elasticities of price and wage inflation are both positively related to $\alpha$, the source of the declining performance of WT originates from the impact on $\lambda_{\pi}, \lambda_{w}$, and $\lambda_{x}$. Differentiating the policy weights with respect to $\alpha$ yields

$$
\begin{aligned}
\lambda_{\pi}^{\prime}(\alpha) & =\frac{1}{2}\left(\frac{\theta^{2}}{\xi_{p}\left(1+\frac{\alpha}{1-\alpha} \theta\right)(1-\alpha)^{2}}\right)>0 \\
\lambda_{w}^{\prime}(\alpha) & =\frac{-\eta}{2 \xi_{w}}<0 \\
\lambda_{x}^{\prime}(\alpha) & =\frac{1}{2}\left(\frac{1+\chi}{(1-\alpha)^{2}}\right)>0
\end{aligned}
$$

which implies that increasing the capital elasticity of output elevates the importance of price inflation and output gap stability while reducing the importance of wage stability. Provided that $\alpha$ is large enough, PT is the preferred regime. For this to occur, however, Figure 6 indicates that $\alpha>0.5$, implying a steady-state capital share of income in excess of 50 
percent and obviously beyond the range of any plausible estimate.

\section{$5 \quad$ Alternative Targeting Regimes}

The success of a regime directed towards stabilizing the price level and the nominal wage is a consequence of the policy inertia it engenders. Recognizing the benefits of inertia for a discretionary central bank has inspired other researchers to devise alternative institutional arrangements capable of delivering such persistence. In this section, I compare the stabilization properties of the aforementioned regimes to a number of delegation schemes that have received considerable attention in the literature.

Walsh (2003) argues that a "speed limit" policy designed to balance the stability of inflation and the one-period change in the output gap imparts a substantial degree of inertia, improving upon the outcome resulting from discretionary optimization of the social welfare function. $^{25}$ I investigate the stabilization properties of implementing a speed limit policy (SL) by delegating the period loss function

$$
L_{t}^{S L}=\pi_{t}^{2}+\tilde{\lambda}_{w} \pi_{t}^{w^{2}}+\lambda_{\Delta x}\left(x_{t}-x_{t-1}\right)^{2}
$$

to the central bank. The value of $\lambda_{\Delta x}$ is chosen optimally according to the same procedure outlined above.

Woodford (1999) demonstrates that modifying the loss function to include a specific objective designed to smooth interest rate changes delivers policy inertia. ${ }^{26}$ I analyze the desirability of assigning an interest rate smoothing (IS) objective by constructing the period

\footnotetext{
${ }^{25}$ The results are demonstrated in a model that features endogenous inflation persistence in the form of a hybrid (two-sided) New Keynesian Phillips curve.

${ }^{26}$ The social loss function in Woodford's model includes an explicit objective for stabilizing the level of the nominal interest rate.
} 
loss function

$$
L_{t}^{I S}=\pi_{t}^{2}+\tilde{\lambda}_{w} \pi_{t}^{w^{2}}+\lambda_{\Delta i}\left(i_{t}-i_{t-1}\right)^{2}
$$

where $\lambda_{\Delta i}$ is selected to minimize the social loss function (10).

Jensen (2002) explores the possibility of targeting the growth rate of nominal income as a means of imparting policy inertia. Denoting $y_{t}$ the log deviation of real output from its steady state level, nominal income growth (NIG1) targeting is characterized by the period loss function

$$
L_{t}^{N I G 1}=\pi_{t}^{2}+\tilde{\lambda}_{w} \pi_{t}^{w^{2}}+\lambda_{N I}\left(y_{t}-y_{t-1}+\pi_{t}\right)^{2}
$$

where $\lambda_{N I}$ measures the optimized relative weight attached to the goal of stabilizing nominal income growth. ${ }^{27}$ Instead of assigning (32), however, some suggest incorporating a nominal income growth target as a substitute for the inflation target while maintaining a separate goal of stabilizing the output gap. Accordingly, I examine this alternative notion of nominal income growth targeting (NIG2) using the period loss function

$$
L_{t}^{N I G 2}=\tilde{\lambda}_{x} x_{t}^{2}+\lambda_{N I}\left(y_{t}-y_{t-1}+\pi_{t}\right)^{2}
$$

where $\tilde{\lambda}_{x}$ is the true relative weight on the output gap.

Nessén and Vestin (2005) advocate targeting a smoothed average of inflation instead of the one-period inflation rate. Even in a purely forward-looking environment, stabilizing average inflation requires an inertial policy response as transitory shocks have lasting effects on variables that are averaged over multiple periods. I test the implications of mandating average inflation targets (AIT) by assigning the period loss function

$$
L_{t}^{A I T}=\bar{f}_{\pi} \bar{\pi}_{t}^{2}+\bar{f}_{w} \bar{\pi}_{t}^{w^{2}}+\tilde{\lambda}_{x} x_{t}^{2}
$$

\footnotetext{
${ }^{27}$ Equilibrium real output and the output gap are related according to the following identity: $x_{t} \equiv y_{t}-y_{t}^{n}$, where $y_{t}^{n}$ represents the natural rate of real output expressed in log deviation form.
} 
Table 5: Statistics For Alternative Regimes Using Baseline Parameters

\begin{tabular}{l|c|c|ccc|c}
\hline \hline Regime & Cons. Equiv. & Weights & S.d. $(\pi)$ & S.d. $\left(\pi^{w}\right)$ & S.d. $(x)$ & Rank \\
\hline IT & 0.529 & $f_{\pi}=0.103, f_{w}=-0.022$ & 0.450 & 0.331 & 2.087 & 7 \\
PT & 0.601 & $g_{p}=0.129$ & 0.424 & 0.472 & 0.568 & 9 \\
WT & 0.486 & $g_{n}=1.173$ & 0.470 & 0.290 & 1.767 & 5 \\
PWT & 0.465 & $g_{p}=1.028, g_{n}=1.228$ & 0.438 & 0.303 & 1.821 & 1 \\
SL & 0.477 & $\lambda_{\Delta x}=0.014$ & 0.441 & 0.307 & 1.885 & 2 \\
IS & 0.477 & $\lambda_{\Delta i}=0.008$ & 0.441 & 0.307 & 1.899 & 3 \\
NIG1 & 0.479 & $\lambda_{N I}=0.014$ & 0.438 & 0.308 & 1.922 & 4 \\
NIG2 & 0.596 & $\lambda_{N I}=0.581$ & 0.450 & 0.445 & 0.756 & 8 \\
AIT & 0.496 & $\bar{f}_{\pi}=2.624, \bar{f}_{w}=3.209$ & 0.446 & .0307 & 2.053 & 6 \\
\hline \hline
\end{tabular}

Note: The welfare costs and standard deviations are multiplied by 100 to express these statistics in percentage points. The right-most column provides an ordinal ranking for each policy. IT - Inflation Targeting, PT Price Targeting, WT - Wage Targeting, PWT - Price and Wage Targeting, SL - Speed Limit Policy, IS - Interest Rate Smoothing, NIG1 - Nominal Income Growth Targeting (no output gap), NIG2 - Nominal Income Growth Targeting (no inflation), AIT - Average Inflation Targeting.

where $\bar{\pi}_{t}=\frac{1}{2}\left(\pi_{t}+\pi_{t-1}\right)$ and $\bar{\pi}_{t}^{w}=\frac{1}{2}\left(\pi_{t}^{w}+\pi_{t-1}^{w}\right)$ are the two-period average rates of price and wage inflation and $\bar{f}_{\pi}$ and $\bar{f}_{w}$ are again chosen to minimize social loss. ${ }^{28}$

Table 5 records the welfare cost of each regime, the optimized weights, and the corresponding standard deviations of $\left\{\pi_{t}, \pi_{t}^{w}, x_{t}\right\}$. Among all regimes considered, PWT generates the smallest welfare cost for the baseline parameter values. The outcomes under SL, IS, NIG1, and AIT, however, are quite competitive with PWT, each garnering a loss equivalent to a permanent reduction in steady-state consumption of less than 0.50 percent. In fact, the cost of moving from PWT to SL is a mere 0.012 percent of consumption.

Despite the absence of an explicit goal for price stability, WT performs nearly as well as SL, IS, and NIG1, and performs better than AIT. The cost of a regime change from SL to WT amounts to a sustained decline in consumption of a only 0.009 percent. Comparing the standard deviations across policies, the only shortcoming of WT relative to betterperforming regimes is a slightly larger volatility of $\pi_{t}(0.470$ under WT and 0.441 under

\footnotetext{
${ }^{28}$ Nessén and Vestin (2005) examine the properties of delegating two-period as well as multi-period average inflation targets.
} 
$\mathrm{SL}$ ). The quantitative impact on welfare, however, appears to be minimal. In contrast, PT engenders the largest welfare cost of all regimes considered. Moving from SL to PT is equivalent to a permanent consumption loss of 0.124 percent. Like NIG2 (the form of nominal income growth targeting proposed by Jensen (2002)), the weakness of PT is the failure to mitigate aggregate wage volatility and the tendency to over-stabilize the output gap.

\section{Concluding Remarks}

The central monetary policy objective in this paper is the minimization of a quadratic, utilitybased social loss function reflecting the microeconomic distortions caused by sticky prices and wages. Given such an objective, the optimal policy is characterized by a commitment to administer an inertial response to shocks that generate an inflation-output gap variance tradeoff. The position taken here is that the central bank conducts monetary policy in a discretionary fashion, that is, commitments are not possible. Accordingly, the task facing a policymaker is the delegation of an alternative loss function to an independent central bank (a targeting regime) that when minimized under discretion, imparts inertia into policy actions that would otherwise be absent under discretionary minimization of the true social loss function. An optimal targeting regime is one that approaches the welfare-maximizing outcome under commitment.

A number of recent studies have concluded that the design of a price level target leads to a more favorable inflation-output gap variance tradeoff than a conventional inflation targeting policy. The evidence presented here indicates that the benefits of targeting the price level alone do not necessarily extend to a model featuring two types of nominal rigidities. For numerous reasonable parameter configurations, price level targeting carries a larger welfare loss than a policy designed to target goods-price and nominal wage inflation despite the ability 
of the former to manufacture an inertial response to transitory supply shocks. It is possible, however, to witness a reversal in their comparative performance for large enough values of $\varepsilon_{p}$ and $\varepsilon_{w}$, or equivalently, for a sufficiently low frequency of price and wage adjustment.

The evidence also suggests that implementing a suitably designed nominal wage target attenuates much of the distortion caused by price and wage rigidities. In fact, wage targeting consistently outperforms price level targeting and inflation targeting for a number of empirically relevant variations in the structural parameters. Evidently, the success of wage targeting is driven primarily by the relative importance of wage stability in the social loss function and on the sensitivity of wage inflation to fluctuations in the output gap, both of which depend on the chosen parameterization. Only in the unlikely event that price shocks are disproportionately large in relation to wage shocks, or that wages are far more flexible than prices, does price level targeting lead to a more favorable welfare outcome than wage targeting.

Finally, the policy exercises reveal that the advantages of wage targeting do not preclude the gains from implementation of a suitably designed price level target. For the baseline parameter values, a combination policy delegating joint price and wage targets delivers an equilibrium outcome nearly as good as the precommitment policy under the timeless perspective. This result is shown to be robust to all variations in the structural parameters considered in the paper. In addition, the combination policy exhibits stabilization properties that are superior to many other delegation schemes that have been the subject of considerable discussion in the literature, namely, speed limit policies, interest rate smoothing, nominal income growth, and average inflation targeting. 


\section{References}

Altig, David; Christiano, Lawrence J.; Eichenbaum, Martin and Linde, Jesper. "Firm-Specific Capital, Nominal Rigidities and the Business Cycle." National Bureau of Economic Research (Cambridge, MA) Working Paper No. 11034, January 2005.

Amato, Jeffrey D. and Laubach, Thomas. "Estimation and Control of an OptimizationBased Model with Sticky Prices and Wages." Journal of Economic Dynamics and Control, May 2003, 27(7), pp. 1181-215.

Ambler, Steve; Dib, Ali and Rebei, Nooman. "Optimal Taylor Rules in an Estimated Model of a Small Open Economy." Bank of Canada Working Paper No. 2004-36, September 2004 .

Blanchard, Olivier Jean and Kahn, Charles M. "The Solution of Linear Difference Equations under Rational Expectations." Econometrica, July 1980, 48(5), pp. 1305-12.

Calvo, Guillermo A. "Staggered Prices in a Utility-Maximizing Framework." Journal of Monetary Economics, September 1983, 12(3), pp. 383-98.

Canzoneri, Matthew B.; Cumby, Robert E. and Diba, Behzad T. "Price and Wage Inflation Targeting: Variations on a Theme by Erceg, Henderson, and Levin," forthcoming in Jon Faust, Athanasios Orphanides, and David Reifschneider, eds., Models and Monetary Policy: Research in the Tradition of Dale Henderson, Richard Porter, and Peter Tinsley. 2004.

Chari, V. V.; Kehoe, Patrick J. and McGratten, Ellen R. "Sticky Price Models of the Business Cycle: Can the Contract Multiplier Solve the Persistence Problem?" Econometrica, September 2000, 68(5), pp. 1151-79.

Christiano, Lawrence J.; Eichenbaum, Martin and Evans, Charles. "Nominal Rigidities and the Dynamic Effects of a Shock to Monetary Policy." Journal of Political Economy, January 2005, 113(1), pp. 1-45.

Clarida, Richard; Galí, Jordi and Gertler, Mark. "The Science of Monetary Policy: A New Keynesian Perspective." Journal of Economic Literature, December 1999, 37(4), pp. 1661-707.

Cooley, Thomas F. and Prescott, Edward C. "Economic Growth and Business Cycles," in Thomas F. Cooley, ed., Frontiers of Business Cycle Research. Princeton: Princeton University Press, 1995, pp. 1-38.

Dittmar, Robert and Gavin, William T. "What Do New-Keynesian Phillips Curves Imply for Price-Level Targeting?" The Federal Reserve Bank of St. Louis Review, April 2000, 82(2), pp. 21-30. 
Erceg, Christopher J.; Henderson, Dale W. and Levin, Andrew T. "Optimal Monetary Policy with Staggered Wage and Price Contracts." Journal of Monetary Economics, October 2000, 46(2), pp. 281-313.

Galí, Jordi; Gertler, Mark and López-Salido, David J. "Markups, Gaps, and the Welfare Costs of Business Fluctuations." National Bureau of Economic Research (Cambridge, MA) Working Paper No. 8850, March 2002.

Goodfriend, Marvin and King, Robert G. "The New Neoclassical Synthesis and the Role of Monetary Policy," in Ben S. Bernanke and Julio J. Rotemberg, eds., NBER Macroeconomics Annual 1997. Cambridge, MA: MIT Pres, 1997, pp. 231-83.

Huang, Kevin X. D. and Liu, Zheng. "Staggered Price-Setting, Staggered Wage-Setting, and Business Cycle Persistence." Journal of Monetary Economics, March 2002, 49(2), pp. 405-33.

Jensen, Henrik. "Targeting Nominal Income Growth of Inflation?" American Economic Review, September 2002, 92(4), pp. 928-56.

Kim, Jangryoul. "Staggered Contracts Models of the Business Cycle: How Much Nominal Rigidity Do We Have?" Federal Reserve Bank of Minneapolis Working Paper No. 2-03, February 2003.

Kim, Jinill; Kim, Sunghyun; Schaumburg, Ernst and Sims, Christopher. "Calculating and Using Second Order Accurate Solutions of Discrete Time Dynamic Equilibrium Models." Federal Reserve Board of Governors Finance and Economics Discussion Series Working Paper No. 2003-61, December 2003.

King, Robert G. and Rebelo, Sergio T. "Resuscitating Real Business Cycles," in John B. Taylor and Michael Woodford, eds., Handbook of Macroeconomics, 1999, Volume 1, Part 2, pp. 927-1007.

Klein, Paul. "Using the Generalized Schur Form to Solve a Multivariate Linear Rational Expectations Model." Journal of Economic Dynamics and Control, September 2000, 24(10), pp. 1405-23.

Levin, Andrew T.; Onatski, Alexie; Williams, John C. and Williams, Noah. "Monetary Policy Under Uncertainty in Micro-Founded Macroeconometric Models," forthcoming in Mark Gertler and Keneth Rogoff, eds., NBER Macroeconomics Annual 2005. Cambridge, MA: MIT Press, 2005.

Mankiw, N. Gregory and Reis, Ricardo. "What Measure of Inflation Should a Central Bank Target?" Journal of European Economic Association, September 2003, 1(5), pp. 1058-86. 
McCallum, Bennett T. and Nelson, Edward. "An Optimizing IS-LM Specification for Monetary Policy and Business Cycle Analysis." Journal of Money, Credit, and Banking, August 1999, 31(3), pp. 296-316.

Mishkin, Frederic S. and Schmidt-Hebbel, Klaus. "One Decade of Inflation Targeting in the World: What Do We Know and What Do We Need to Know?" in Norman Loayza and Raimundo Soto, eds., Inflation Targeting: Design, Performance, Challenges. Santiago, Chile: Central Bank of Chile, 2002, pp. 117-219.

Nessén, Marianne and Vestin, David. "Average Inflation Targeting." Journal of Money, Credit, and Banking, October 2005, 37(5), pp. 837-63.

Rabanal, Pau and Rubio-Ramírez, Juan F. "Comparing New Keynesian Models of the Business Cycle: A Bayesian Approach." Journal of Monetary Economics, September 2005, 52(6), pp. 1151-66.

Rogoff, Kenneth. "The Optimal Degree of Commitment to an Intermediate Monetary Target." Quarterly Journal of Economics, November 1985, 100(4), pp. 1169-89.

Rotemberg, Julio J. and Woodford, Michael. "An Optimization-Based Econometric Framework for the Evaluation of Monetary Policy," in Ben S. Bernanke and Julio J. Rotemberg, eds., NBER Macroeconomics Mnnual 199\%. Cambridge, MA: MIT Press, 1997, pp. 297-346.

Rudebusch, Glenn D. and Svensson, Lars E. O. "Policy Rules for Inflation Targeting," in John B. Taylor, ed., Monetary Policy Rules. Chicago and London: University of Chicago Press, 1999, pp. 203-46.

Sbordone, Argia M. "A Limited Information Approach to the Simultaneous Estimation of Wage and Price Dynamics." Manuscript, Rutgers University, 2004.

Smets, Frank and Wouters, Raf. "An Estimated Dynamic Stochastic General Equilibrium Model of the Euro Area." Journal of the European Economic Association, September 2003, 1(5), pp. 1123-75.

- "Comparing Shocks and Frictions in U.S. and Euro Area Business Cycles: A Bayesian DSGE Approach." Journal of Applied Econometrics, March 2005, 20(2), pp. 161-83.

Söderlind, Paul. "Solution and Estimation of RE Macromodels With Optimal Policy." European Economic Review, April 1999, 43(4-6), pp. 813-23.

Söderström, Ulf. "Targeting Inflation With a Role for Money." Economica, November 2005, 72(288), pp. 577-96. 
Svensson, Lars E. O. "Inflation Forecast Targeting: Implementing and Monitoring Inflation Targets." European Economic Review, June 1997, 41(6), pp. 1111-46.

- "Inflation Targeting as a Monetary Policy Rule." Journal of Monetary Economics, June 1999a, 43(3), pp. 607-54.

. "Price Level Targeting vs. Inflation Targeting: A Free Lunch." Journal of Money, Credit, and Banking, August 1999b, Part 1, 31(3), pp. 277-95.

Svensson, Lars E. O. and Woodford, Michael. "Implementing Optimal Policy Through Inflation-Forecast Targeting," in Ben S. Bernanke and Michael Woodford, eds., Inflation Targeting. Chicago: University of Chicago Press, 2005, pp. 19-83.

Vestin, David. "Price-Level Targeting Versus Inflation Targeting in a Forward-Looking Model." Sveriges Riksbank Working Paper No. 60, May 2000.

Walsh, Carl E. "Speed Limit Policies: The Output Gap and Optimal Monetary Policy." American Economic Review, March 2003, 93(1), pp. 265-78.

Woodford, Michael. "Optimal Monetary Policy Inertia." National Bureau of Economic Research (Cambridge, MA) Working Paper No. 7261, August 1999.

. Interest and Prices: Foundations of a Theory of Monetary Policy. Princeton and Oxford: Princeton University Press, 2003.

- "Firm-Specific Capital and the New-Keynesian Phillips Curve." International Journal of Central Banking, September 2005, 1(2), pp. 1-46. 